This is an electronic reprint of the original article. This reprint may differ from the original in pagination and typographic detail.

Author(s): Junttila, Juha; Myllymäki, Valtteri; Raatikainen, Juhani

Title: $\quad$ Pricing of Electricity Futures Based on Locational Price Differences : The Case of Finland

Year: $\quad 2018$

Version:

Please cite the original version:

Junttila, J., Myllymäki, V., \& Raatikainen, J. (2018). Pricing of Electricity Futures Based on Locational Price Differences : The Case of Finland. Energy Economics, 71, 222-237. https://doi.org/10.1016/j.eneco.2018.02.018

All material supplied via JYX is protected by copyright and other intellectual property rights, and duplication or sale of all or part of any of the repository collections is not permitted, except that material may be duplicated by you for your research use or educational purposes in electronic or print form. You must obtain permission for any other use. Electronic or print copies may not be offered, whether for sale or otherwise to anyone who is not an authorised user. 


\section{Accepted Manuscript}

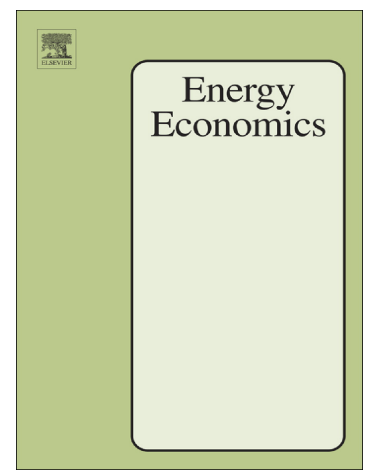

Juha Junttila, Valtteri Myllymäki, Juhani Raatikainen

PII: $\quad$ S0140-9883(18)30076-8

DOI: $\quad$ doi:10.1016/j.eneco.2018.02.018

Reference: $\quad$ ENEECO 3927

To appear in:

Received date: $\quad 18$ May 2017

Revised date: $\quad 10$ February 2018

Accepted date: $\quad 23$ February 2018

Please cite this article as: Juha Junttila, Valtteri Myllymäki, Juhani Raatikainen, Pricing of Electricity Futures Based on Locational Price Differences: The Case of Finland. The address for the corresponding author was captured as affiliation for all authors. Please check if appropriate. Eneeco(2018), doi:10.1016/j.eneco.2018.02.018

This is a PDF file of an unedited manuscript that has been accepted for publication. As a service to our customers we are providing this early version of the manuscript. The manuscript will undergo copyediting, typesetting, and review of the resulting proof before it is published in its final form. Please note that during the production process errors may be discovered which could affect the content, and all legal disclaimers that apply to the journal pertain. 


\title{
Pricing of Electricity Futures Based on Locational Price Differences: The Case of Finland
}

\author{
Juha Junttila*, Valtteri Myllymäki** and Juhani Raatikainen $^{* * *}$
}

This version $3 / 1 / 2018$

\begin{abstract}
We find that the pricing of Finnish electricity market futures has been inefficient during the latest 10 years, when the trading volumes of Electricity Price Area Differentials (EPADs) have more than doubled. Even though the calculated futures premium on EPADs is related to some risk measures and the variables capturing the demand and supply conditions in the spot electricity markets, there has been a significant positive excess futures premium in the Finnish market, and financial market participants should have been able to utilize this also in economic terms. This finding is new and relevant for the participants of the Nordic electricity markets also in the future, because both the speculative and hedging-based trading is increasing in the Nordic markets.
\end{abstract}

Keywords: Risk premium, Electricity futures, EPAD, Nordic electricity market, Arbitrage JEL Classifications: G13, G14, Q41

\footnotetext{
* Address: University of Vaasa, School of Accounting and Finance, PO BOX 700, 66401 Vaasa, Finland, tel. +358-29-4498701, email: juha.junttila@uwa.fi.

** Address: Fortum Oyj, PO Box 100, 00048 Fortum, FINLAND, e-mail:valtteri.myllymaki@fortum.com

*** Corresponding author, Address: Jyväskylä University School of Business and Economics, Po Box 35, FI40014 University of Jyväskylä, FINLAND, tel +358-40-5767835, e-mail: juhani.raatikainen@jyu.fi.
} 


\section{Introduction}

Electricity markets around the world have undergone a wave of deregulation and liberalization since the 1990s. The Nordic electricity market is a typical example of this development. In the Finnish and other Nordic markets, vertically integrated monopolies that used to manage production, transmission and sales of electricity have been restructured. Nowadays production and sales operate under free competition, while nation-wide transmission and communal-level distribution networks remain regulated natural monopolies. A natural extension to the restructured wholesale markets has been the development of derivatives markets, since electricity is a homogenous commodity in a given geographical area with sufficient transmission network, capacity and similar power system. Wellfunctioning derivatives market is of high importance for market participants, since electricity is practically non-storable, and hence, subject to extreme price volatility.

Similar to retail and wholesale markets, pricing of derivatives written on different reference prices in the electricity markets has gained notable academic interest. The focus of research has unsurprisingly been on the derivatives in the largest and most mature markets, such as the ones in particular states in the US, the Nordic countries, and Germany/Austria (see e.g. Bessembinder and Lemmon 2002; Redl et al., 2009; Gjolberg and Brattested 2011; and Fleten and Hagen, 2015). Due to physical transmission congestion, local prices may differ substantially from the reference prices causing market participants to incur locational basis risks.

The Nordic market has been divided into 15 bidding areas based on transmission capacities between the areas, and Finland composes one area. Electricity Price Area Differentials (EPADs) are used to hedge price differences between a bidding area and the Nordic system price. Furthermore, Marckhoff and Wimschulte (2009) note that explicit exchange-listed derivatives on the area prices do not exist, since the market was designed on purpose so that overall liquidity would not split among several products. In bidding areas where the area prices differ significantly from the system price, hedging is based on dealing with two separate contracts, which together yield an implied futures contract on the area price, that is, by using 1) a futures contract based on the system price; and 2) futures contract, commercially known as an EPAD, based on the area price difference.

Contrary to the futures on electricity reference prices, such as the Nordic system price, the previous literature on EPADs is very limited. To our knowledge, only few studies (Marckhoff 
and Wimschulte, 2009; Kristiansen, 2004a and b; Spodniak et al., 2017; Spodniak and Collan, 2018) on EPADs pricing have been published in academic journals previously. In addition, EPADs have been studied by Spodniak et. al. (2014) and Spodniak (2015) in conference papers. The main contribution of our research is to provide new empirical results on EPADs pricing. All the previous studies have focused on the relationship between the EPADs and respective area price difference or the ex-post futures premium, and we follow this approach, too. However, unlike Marckhoff and Wimschulte (2009) Spodniak et. al. (2014) or Spodniak (2015), we attempt to link the ex-post futures premium of EPADs also to abnormal supply and demand conditions that might be of high importance specifically in the Finnish electricity market.

Electricity prices (and associated costs) are of particular importance to the competitiveness of Finnish economy due to Finland's cold climate and energy-intensive industry's large share of GDP that cause Finland to have one of the largest energy intensities, that is, the ratio of gross inland energy consumption to GDP in the EU. The electricity market spot price in Finland has differed substantially from the Nordic system price. For example, in 2015 the Finnish monthly area spot price exceeded the Nordic system spot price on average by $54.6 \%$, exposing the Finnish market participants to a significant basis risk. Moreover, between 2006 and 2015 the system price and the area spot prices of Norway, Sweden and Denmark were on average $10.47 \%, 5.97 \%, 10.72 \%$ and $2.86 \%$ lower than the spot price in Finland, respectively. Furthermore, the Finnish area price difference has widened during the last years.

A natural question for the Finnish market participants is whether the area price differences are reflected in the EPAD prices. Self-evidently, this question is of interest for market participants hedging the future electricity consumption and generation. Speculators alike are interested to discover whether there are profitable trading strategies to be exploited. Prices of derivatives have also wider ramifications. In a market economy they provide price signals, which are essential for an efficient allocation of resources. EPADs prices could for example provide signals for investments in transmission capacity, or production planning of energyintensive industry or electricity generators. Furthermore, a regulatory point of view matters here, too. The European Union is harmonizing the European electricity market, and EPADs are under review. Regulators are inclined to discover, whether EPADs can efficiently be used to hedge against the area price difference, or should an alternative market structure be established, where the transmission system operators (TSOs) would for example issue financial transmission rights (FTRs) (Spodniak et al., 2014). 
Following all this motivation, we attempt to contribute to the existing literature by analysing first the size of the futures bias for Finnish EPADs, and how biased forecasts do the EPAD futures prices provide for the realized difference between the Finnish area and the Nordic system price. Furthermore, we want to find out which market factors can help to explain the possibly observed bias, or in other words, is the bias a consequence of market inefficiency, $a$ risk premium, or a combination of them.

To answer these research questions we use monthly observations from January 2006 to January 2016 on the Finnish EPADs or the difference between the realized area spot price and futures price for the corresponding delivery period. Futures price data were obtained from a third party that have received it from the Nasdaq OMX Commodities exchange, whereas the spot prices were obtained from the Nord Pool, the physical power exchange in the Nordic market.

Our results imply that on average there has been a positive bias in the pricing of monthly Finnish EPADs. In other words, the futures price before the delivery period has exceeded the spot price difference in the respective delivery period in general. However, the bias is statistically significant only after excluding the extreme observations from the sample. Furthermore, the bias seems to exhibit seasonality being the highest during autumn and winter, and the lowest and even negative during the summer time. Both risk considerations and market efficiency seem to explain the bias and we find only little support for the findings of e.g. Bessembinder and Lemmon (2002), or Marckhoff and Wimschulte (2009), but we do find that the bias has increased after 2012. This could be attributed to the decrease in Russian imports, which may have widened the imbalance between the electricity consumers and generators that naturally hedge the Finnish area price leading to a positive premium in the futures market. Finally, we also document a feedback mechanism (bi-directional causality) between the Finnish area price difference and the EPADs, which could hint that the futures market may be inefficient to some extent.

The rest of this study is structured as follows. In section two we give a short overview on the specific characteristics of Nordic and especially the Finnish electricity markets to lay some background regarding the market specific factors relevant for our empirical analysis. In section 3 we present the theoretical framework and results from some previous studies to serve as the background for our empirical analysis. Section 4 describes the data and empirical 
methodology used for our analysis, section 5 reports the empirical results, and finally, section 6 gives conclusions and suggestions for further research.

\section{Characteristics of the Nordic and Finnish electricity markets}

The Nordic market is one of the largest and was among the first liberalized electricity markets. The history of the common Nordic market dates back to 1991, when Norway deregulated its wholesale electricity market. This formed a model for Sweden, Finland, and Denmark, that joined the common exchange titled Nord Pool, in 1996, 1998 and 2000, respectively. Estonia, Lithuania and Latvia joined the exchange in 2010, 2012 and 2013, and in 2014 Nord Pool was coupled with the Western European spot markets. In practice this implies that a single algorithm is used to compute spot prices across the involved exchanges and to allocate the cross-border capacities. Currently the physical exchange is owned by the Nordic and Baltic transmission system operators (TSOs, see Nord Pool, 2015a and b). The first financial contracts on the system price were introduced in 1997, while the trading of EPADs, or CfDs (contracts for differences, as they were called at that time), were launched in 2000. In 2002 the physical and financial exchanges were demerged into separate companies, and in 2008 the financial exchange was acquired by Nasdaq OMX and merged into Nasdaq OMX Commodities (Nasdaq OMX, 2015).

Wholesale markets in the Nordic countries can be divided into short-term physical market and longer-term financial market. Market participants in the physical market include retailers and large industrial consumers, generators and trading houses. They have to be physically connected and to have a balance agreement with the TSO in the bidding area they are residing, as the physical market balances the supply and demand of electricity at every instant. In the day-ahead spot market the participants purchase and sell electricity for each hour for the next day according to their preliminary supply or consumption plans, which yields the spot prices for each hour. In the secondary market the trading is continuous, and participants can manage unanticipated imbalances or optimize their supply or purchase plans up to one hour before the delivery hour. Finally, the ancillary market maintained by the TSOs balances the power system in real-time, maintains system security and quotes the balance prices, which are used in settling the imbalances, i.e. the difference between actual generation (consumption) and electricity sold (purchased). The TSO of Finland is called Fingrid.

Trading in the day-ahead physical market takes place either bilaterally in the OTC list or in the Nord Pool market. The physical spot market is operational 365 days a year and produces 
spot prices for each hour. Over 300 market participants from the Nordic and Baltic countries submit daily their bids to the Nord Pool before 12:00 CET. Bids are like individual demand and supply curves: they reveal the quantity demanded and supplied at a given price. Nord Pool aggregates the bids to the market-wide supply and demand curves for each hour and the spot price clears the market. The individual orders are fulfilled if price at which the quantity demanded (supplied) is above (below) the spot price. This procedure is repeated for each hour yielding a spot price for every hour, and results for the next day are published normally before 13:00 CET. Daily, weekly, monthly, quarterly and annual spot prices are computed as simple averages from the hourly prices.

The system price is computed from the aggregated supply and demand curves assuming no transmission constraints, yielding a reference price for the whole Nordic area. In a competitive market the clearing spot price then represents the marginal cost of the last generation unit needed to meet the given, highly inelastic demand. The area spot prices are computed similarly for each hour but there the exchange aggregates the orders only for each bidding area and takes into account the available transmission capacity which is determined by the TSOs. The flow of power is directed from the surplus (lower price) area to the deficit (higher price) area and the transmission capacity between them is utilized to the maximum, so the aggregated supply (demand) curve in the deficit (surplus) area is shifted in parallel right to the extent of maximum transmission capacity, which increases (decreases) the price in the surplus (deficit) area. If the transmission computed by the Nord Pool exceeds the available capacity set by the TSOs for example from SE1 bidding area to Finland, a higher spot price clears the Finnish market. Conversely, if the computed flow of power in all areas is within the limits set by TSOs, then the entire market has one common price, called the system price (Nord Pool, 2015b). The formation of area spot prices is depicted in Figure 1 whereas Figure 2 presents the bidding areas as well as the maximum transmission capacities between the areas. 

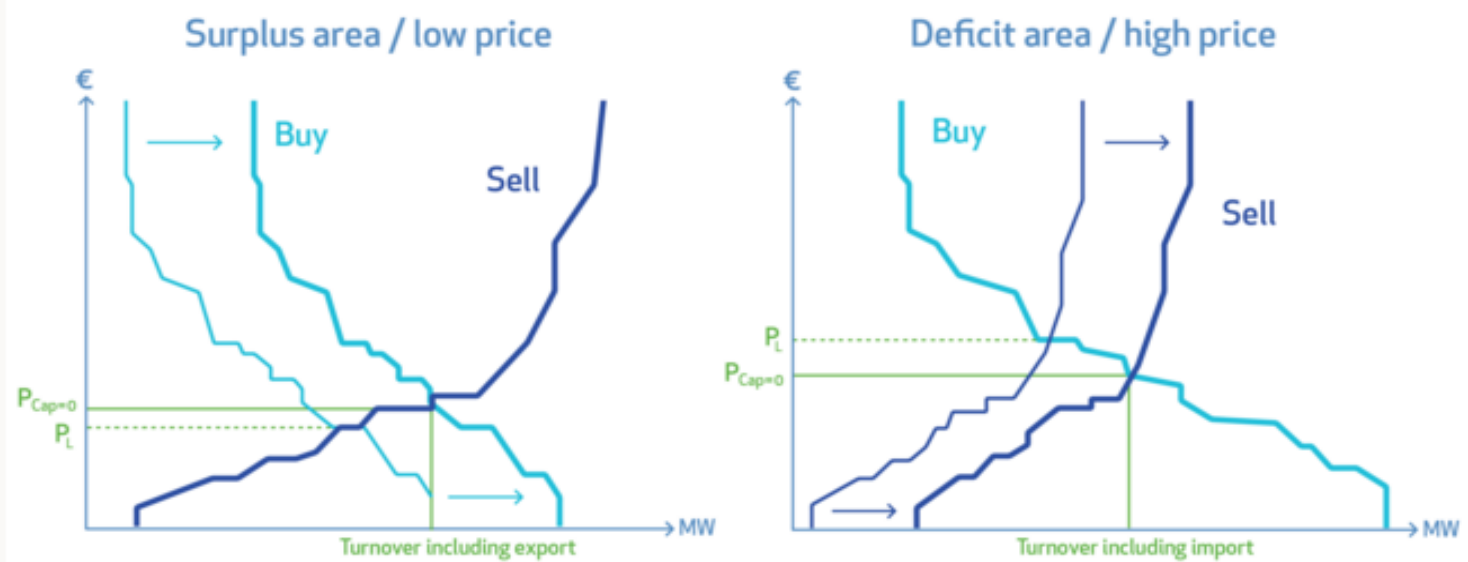

Fig. 1. Formation of area prices (Source: Nord Pool 2015b).

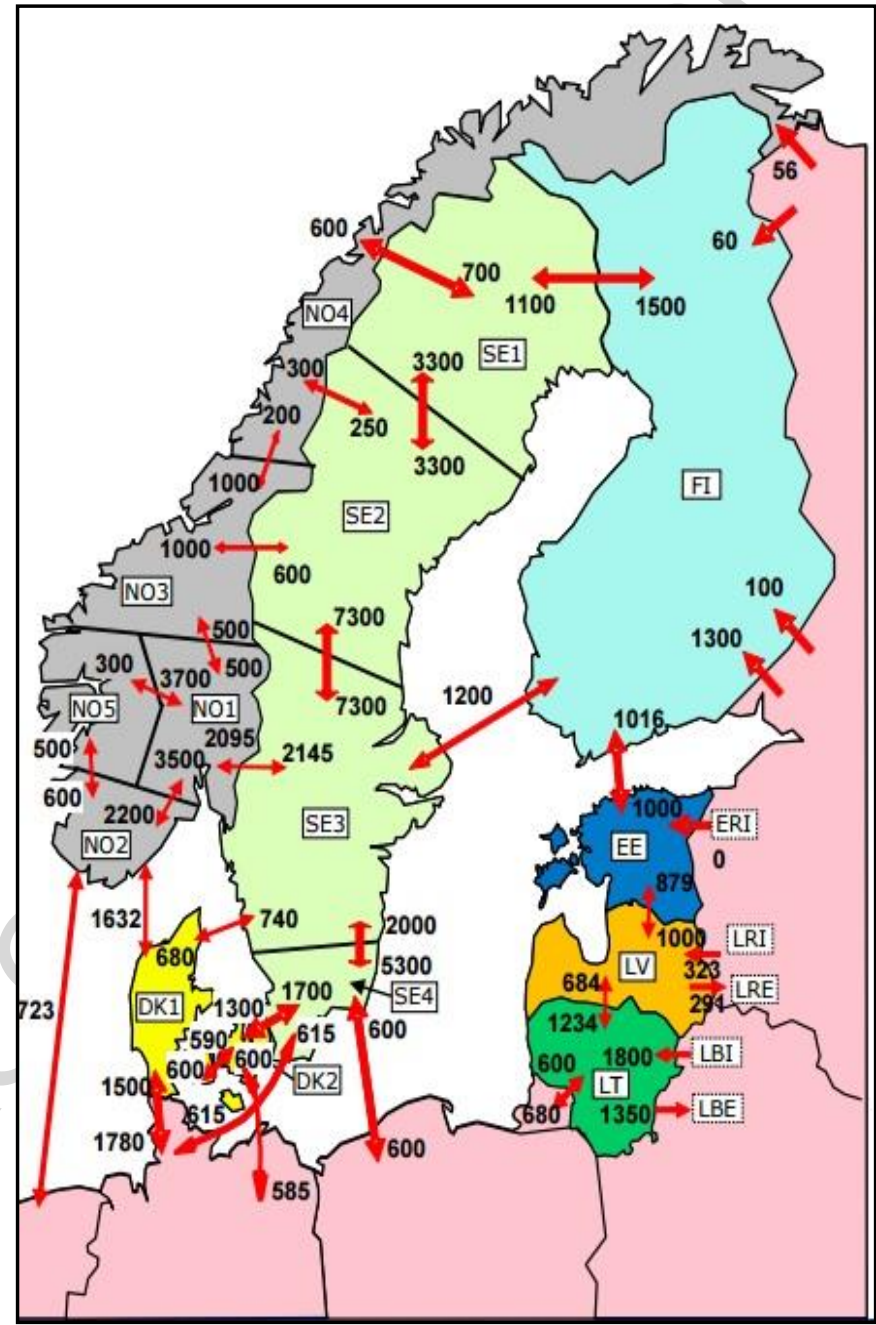

Fig. 2. Bidding areas and maximum transmission capacities (MW) in the Nordic market (Source: Entso-E 2015). 
The financial market in turn allows the market participants to hedge their generation or consumption volumes in the longer-term and provides the access to the market also for the financial players, such as banks or hedge funds. In the Nordic market longer-term hedging can be either done over-the-counter (OTC) or in the Nasdaq OMX Commodities (NOC) exchange, where standardized futures, forwards (commercial name deferred settlement (DS) futures) and options are listed and traded on weekdays from 08:00 am to 16:00 (CET). NOC also provides clearing services, and in fact, a significant amount of OTC trades are cleared in the NOC. Futures are contracts with a delivery period from one day to week, whereas forwards' delivery period is one month, quarter or year. Before they expire, the yearly contracts are cascaded into quarterly contracts, and quarterly contracts into monthly contracts. Neither forwards nor futures lead to physical delivery of electricity: they are cashsettled in the delivery (or settlement) period.

EPADs' delivery period ranges from one week to one year. However, in practice the weekly contract is illiquid, and hence, impractical for hedging. Monthly EPADs are listed for four months, quarterly EPADs for four quarters, and yearly EPADs four years prior to the delivery period.

Futures and forward contracts differ by their settlement. Forwards are settled only during the delivery period, whereas futures are settled also on a daily basis during the trading period. In theory, this has some implications for their pricing, as the cash flows occur at different times. However, in practice, this effect is negligible. If interest rates are a given function of time, i.e. not stochastic, futures and forward prices are equal (Hull, 2009, 110). In this study, we make no distinction between them and from now on refer to both of them as the "futures".

All the contracts in NOC are quoted as $€ / \mathrm{MWh}$ (with the minimum tick size of $0.01 €$ ) and refer to a baseload of one MW during the delivery period, which varies from 24 to 8760 hours. For a system futures contract the underlying price is the arithmetic average of hourly system spot price during the delivery period, whereas for an EPAD, the underlying price is the arithmetic average of the difference between the hourly area and system spot prices during the delivery period.

To understand how different futures can be used in hedging we give a simple example. Assume a Finnish industrial consumer with constant electricity consumption of one MWh per hour participates on the wholesale markets and intends to fix the purchase price for the next year (=delivery period). It purchases one MWh per each hour from the spot market, a one 
year contract written on system price, and a one year EPAD written on the Finnish area price difference. Now, suppose the futures prices are fixed at $25 € / \mathrm{MWh}$ for the system future, and $7 € /$ MWh for the Finnish EPAD, and that next year the average system and Finnish spot prices realize at $26 € / \mathrm{MWh}$ and $35 € / \mathrm{MWh}$, respectively. The realized area price difference is then $9 € / M W h$. Hence, the cash flows for the consumer will be the following:

$$
8760 \mathrm{~h} \times(-1 \mathrm{MW}) \times 35 € / \mathrm{MWh}=-306600 € \text { for the spot delivery, }
$$

$8760 \mathrm{~h} \times(1 \mathrm{MW}) \times(26-25) € / \mathrm{MWh}=8760 €$ for the long position in a system futures contract and finally,

$$
8760 \mathrm{~h} \times(1 \mathrm{MW}) \times(9-7) € / \mathrm{MWh}=17520 € \text { for the EPAD }
$$

Hence, the total cost is $306600 €-8760 €-17520 €=280320 €$, and when the annual purchase volume is $8760 \mathrm{MWh}$, the average purchasing price realizes at $280320 € / 8760 \mathrm{MWh}$ $=32 € / \mathrm{MWh}$, which is the sum of the two hedges.

Liquidity among the different products and maturities varies a lot. Figures 3 and 4 describe the development of trading volumes in the past years for the futures on system price and Finnish EPADs on trades conducted or cleared at the Nasdaq OMX Commodities. Comparing annual turnovers, it is evident that the Finnish EPADs are far less liquid than the system futures. In 2015 the turnover of Finnish EPADs constituted barely half of the consumption in Finland, whereas for the system futures and the respective consumption in the Nordic and Baltic region the same ratio was nearly four in 2013. The trading of Finnish EPADs is concentrated on yearly contracts, and usually takes place at the OTC market. 




Fig. 3. Trading volumes (TWh) for Nordic system futures in 1998-2013. (Source: NordReg 2014, 46)



Fig. 4. Trading volumes (TWh) for Finnish EPADs in 2006-2015. (Sourece: Nasdaq OMX Commodities, 2015).

Regarding again the physical market, the Finnish electricity market has a number of important different characteristics compared to the whole Nordic market (see Figure 5). First, although nuclear and hydropower productions constitute a considerable share of the generation mix also in Finland, the share of hydropower is much lower than in the Nordic market and relatively larger share of it is based on unregulated, run-on-river hydro assets. Second, Finland also has less renewable and more fossil fuels based generation especially in 
the form of CHP generation. The amount of plain condense generation has decreased as it has become less profitable due to the decreasing spot prices. Finally, and most importantly, as can be seen from the continuous difference between consumption and generation values, Finland is a net importer of electricity throughout the year.

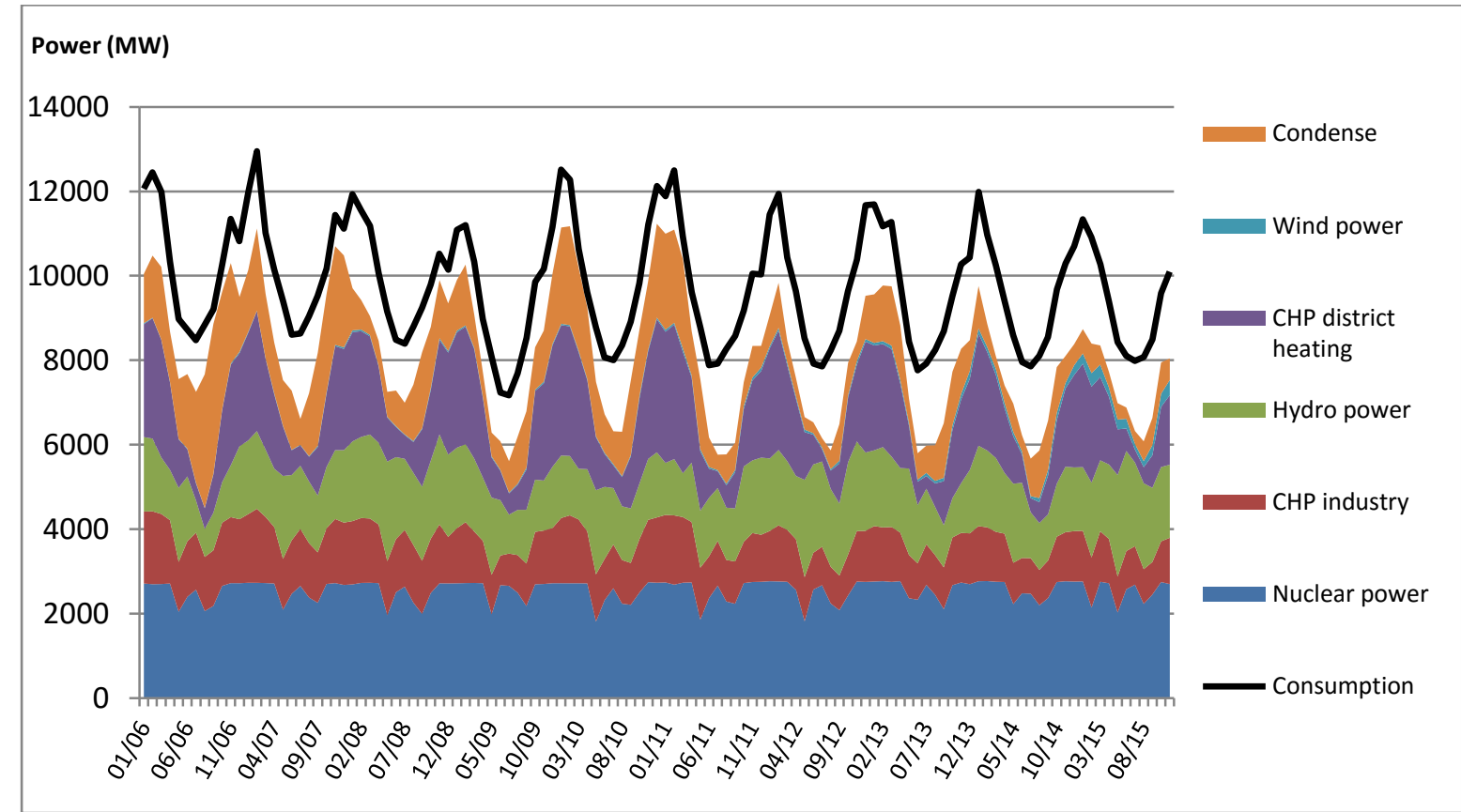

Fig. 5. Generation and consumption (average power per month) in Finland 2006 - 2015. (Source: Finnish Energy Industries, 2016a and 2016)

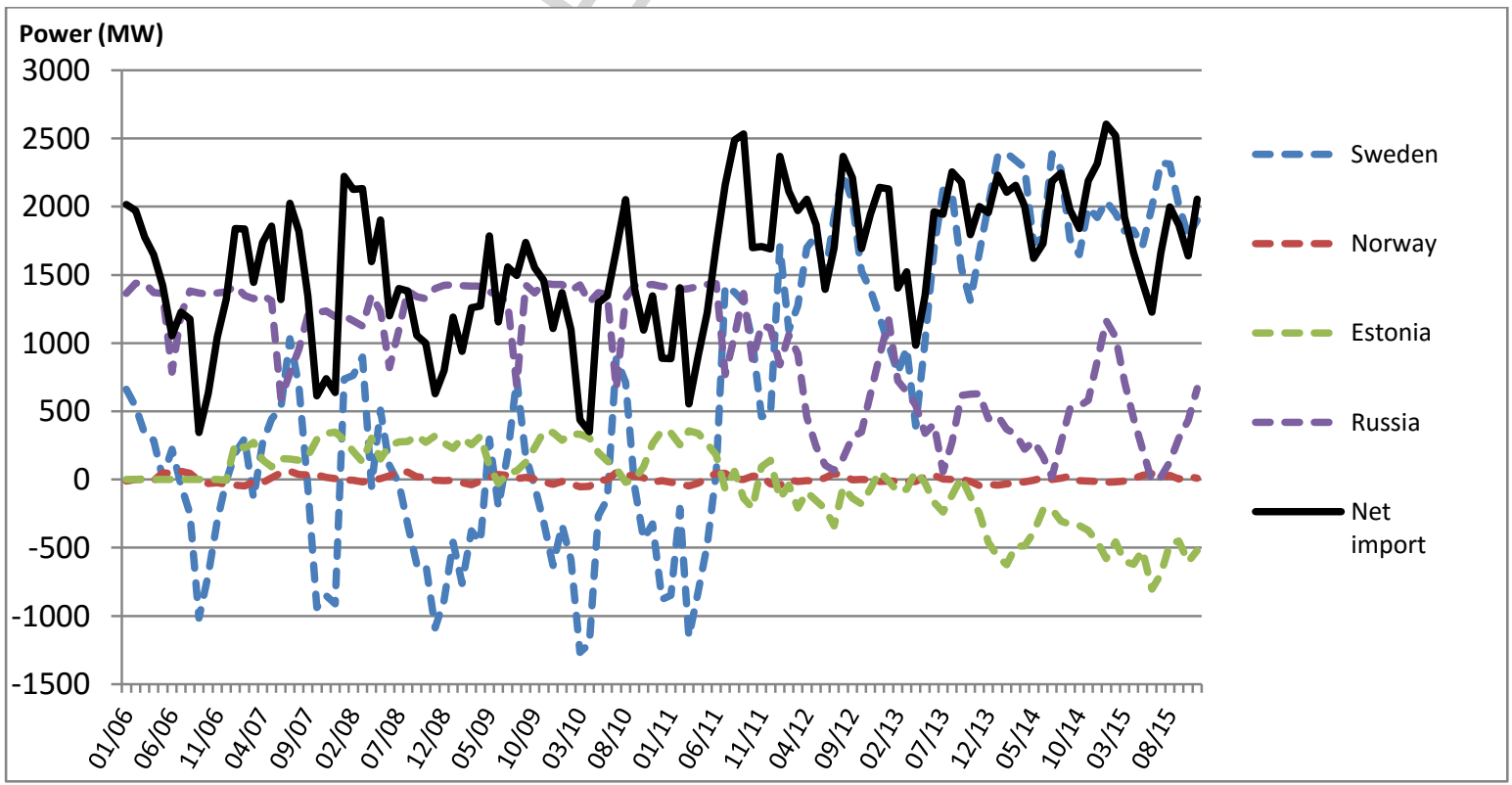

Fig. 6. Net import and export (average power per month) to and from Finland 2006 - 2015. (Source: Finnish Energy Industries, 2016a). 
As seen from Figure 6, until 2011 Finland both exported and imported electricity to Sweden on a monthly basis, and the imports from Russia were relatively stable. However, in late 2011 Russia introduced capacity tariffs on its market, and as a consequence, imports from Russia decreased on weekdays during the peak hours (Viljainen et al., 2012). Reduced imports have primarily been replaced by exports from Sweden that increased the price difference between Sweden and Finland (see Table 1 below). While the price difference between the Finnish area and Nordic system price has not increased notably in absolute terms, in relative terms the difference has widened substantially.

Table 1.

Annual spot prices (€/MWh) (system (SYS), Sweden (SE), Finland (FI), Norway (NO) and Denmark (DK)) and the relative average differences compared to Finland. Swedish, Norwegian and Danish prices are computed as averages of the area prices within the countries. (Nord Pool)

\begin{tabular}{r|ccccc} 
Year & SYS & SE & FI & NO & DK \\
\hline 2006 & 48.59 & 48.12 & 48.57 & 49.10 & 46.36 \\
2007 & 27.93 & 30.25 & 30.01 & 27.64 & 32.71 \\
2009 & 44.73 & 51.12 & 51.02 & 44.93 & 56.54 \\
2010 & 35.02 & 37.01 & 36.98 & 34.64 & 37.97 \\
2011 & 47.05 & NA & 49.30 & 46.80 & 48.69 \\
2012 & 31.20 & 32.51 & 36.64 & 30.30 & 36.95 \\
2013 & 38.10 & 39.44 & 41.16 & 38.17 & 39.29 \\
\hline 2014 & 29.61 & 31.59 & 36.02 & 29.37 & 31.41 \\
2015 & 20.98 & 21.81 & 29.66 & 20.40 & 23.70 \\
\hline Aver. diff. (\%) & -10.47 & -5.97 & - & -10.72 & -2.86 \\
\hline & & & & & \\
\hline
\end{tabular}




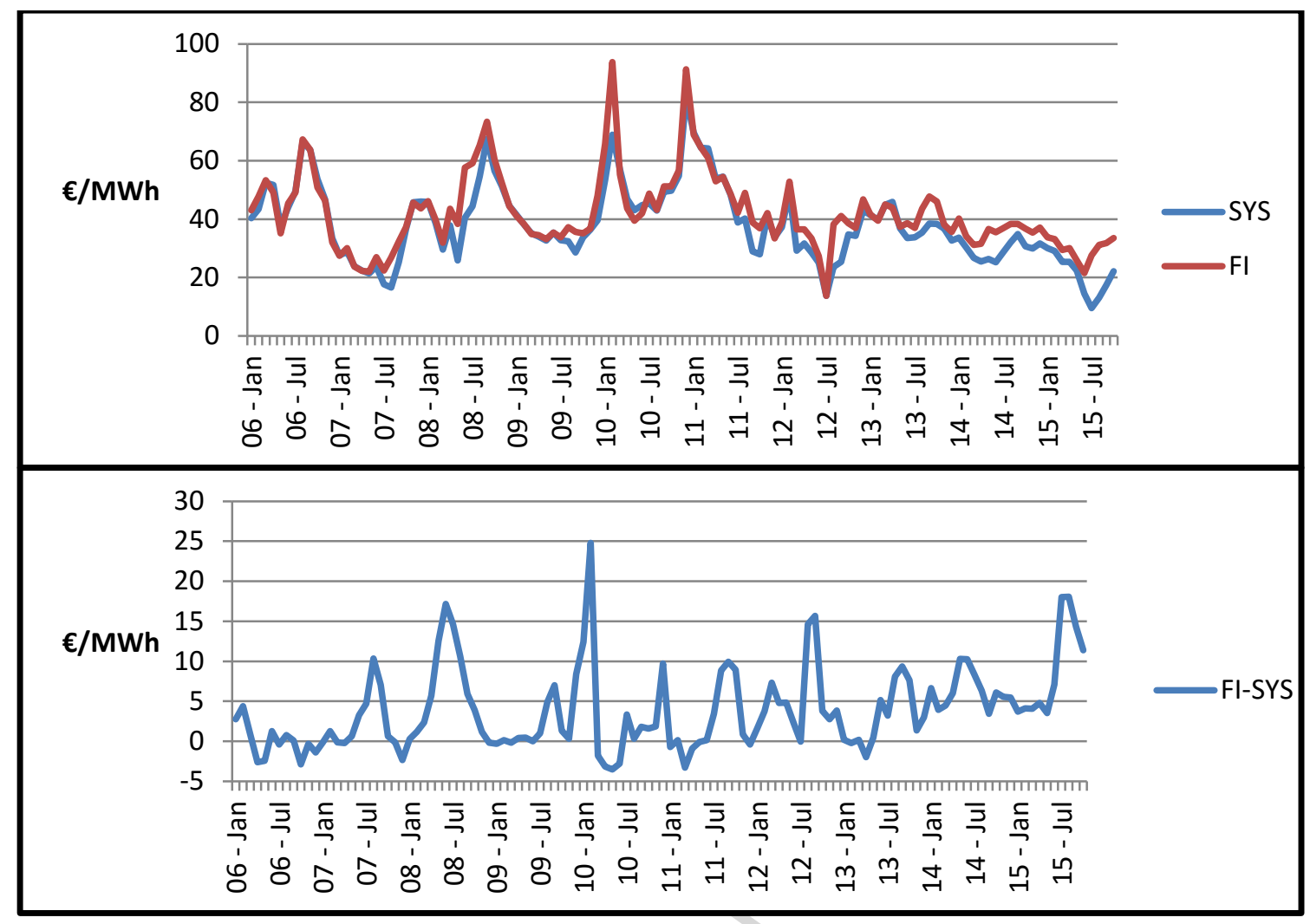

Fig. 7. Monthly Nordic system price (SYS), Finnish spot price (FI) and the difference between them (FI-SYS, i.e., the area price difference), between January 2006 - January 2016.

The key interesting time series for our empirical analyses, i.e., the development of the monthly system spot price, Finnish area price and the Finnish area price difference are depicted in Figure 7. In the past years the system price has been historically low as the volume of price independent renewable (mainly wind) production has increased due to subsidies, prices of fossil fuels have decreased, weather has been relatively mild during winters, and the availability of hydropower has not been particularly tight. On the other hand, the sharp increases in the system price during winters 2009 - 2010 and 2010 - 2011 can at least partially be attributed to the facts that weather was colder than on average and hydropower availability was below the average.

Evidently, the Finnish electricity market pricing seems to have some different characteristics and underlying factors affecting the pricing in the physical and financial segments of the overall market compared to the other Nordic countries, and because Finland seems to always be a net importer of electricity, there is clearly a need for empirical analysis that would reveal the key phenomena affecting the pricing of EPADs. Furthermore, the previous literature on EPADs consists only of few studies, and they indeed have tended to document positive bias for the Finnish EPADs. However, some of the studies are outdated, and the 
determinants of the bias have remained largely unclear. This obviously calls for more research on this theme. In the next section we give details of the theoretical background behind our empirical analyses.

\section{Theoretical background and previous studies}

We use the expectations theory of futures pricing as the main theoretical background for our empirical analyses. Following Hull (2009), in this case the futures price at time $t$ for delivery at time $T$, that is, $F_{t, T}$ is based on equation

$$
F_{t, T}=E_{t}\left(S_{t+T}\right) e^{(r-k) T}
$$

where $E_{t}\left(S_{t+T}\right)$ is the expected spot price at time $t+T, r$ is the risk-free interest rate, $k$ the riskadjusted discount rate, and $T$ measures the time to maturity. Denoting $(k-r)=P$, which can be interpreted as the risk premium, and substituting it into equation (3.1), yields

$$
F_{t, T}=E_{t}\left(S_{t+T}\right) e^{(-P) T}
$$

and in a linear form for the $\log$ of prices, assuming the risk premium $P$ is not time-varying, equation (3.2.) is given as

$$
F_{t, T}=E_{t}\left(S_{t+T}\right)-P .
$$

The risk premium in the expectations theory can be explained in two ways. For an investment asset, Hull (2009) explains it as the correlation between the returns of a futures contract in question and a broader, well-diversified stock and bond portfolio. However, for electricity markets and EPAD pricing the approach by Anderson and Danthine (1983), that considers the microstructure of the market seems more appropriate, or as Gjolberg and Brattested $(2011,4)$ note "in a balanced market, i.e., market where short hedging demand is exactly matched by long demand, the futures price should equal the expected spot price" and that "in a wellfunctioning market with unbalanced hedging demand, the futures price deviates from the expected spot price by the risk premium".

Vehviläinen (2002) details the basic pricing ideas of electricity derivatives in competitive markets. He notes that "electricity that is delivered at any given future time is a separate asset from the electricity that is delivered now" and that "the non-storability of electricity makes the electricity market different from the financial and other commodity markets" (Vehviläinen, 2002, 49). Due to the non-storability he lists two unique features of the electricity futures pricing compared to other commodities. First, he notes that the electricity 
spot prices, i.e. the underlying prices for futures, are subject to spikes and volatility, because supply and demand has to be in balance all the time. Hence, they are difficult to model. Second, Vehviläinen $(2002,47)$ adds that "at no time it is allowed to own spot electricity as an asset" meaning that the market is incomplete, because it is not possible to hedge financial futures by creating a mimicking portfolio with a bank account and physical spot electricity. Based on this, he proposes that in a competitive market the electricity futures prices converge to risk-adjusted expected future spot price, as given in equation 3.2. Moreover, he notes that the final quotation of the futures price is the market's risk-adjusted expectation of the spot price at the delivery period.

In Figure 8 we clarify the notation used throughout our empirical analysis. $S_{t}^{T}$ denotes the spot price in the delivery month $T$ and $F_{t}^{T-1, T}$ the futures price whose settlement occurs in the delivery period $T$. Note that the futures price is observed at $T$-1, i.e., before the delivery period $T$ at the end of the previous month.

$F_{t-2}^{T-3, T-2} \quad F_{t-1}^{T-2, T-1} \quad F_{t}^{T-1, T}$

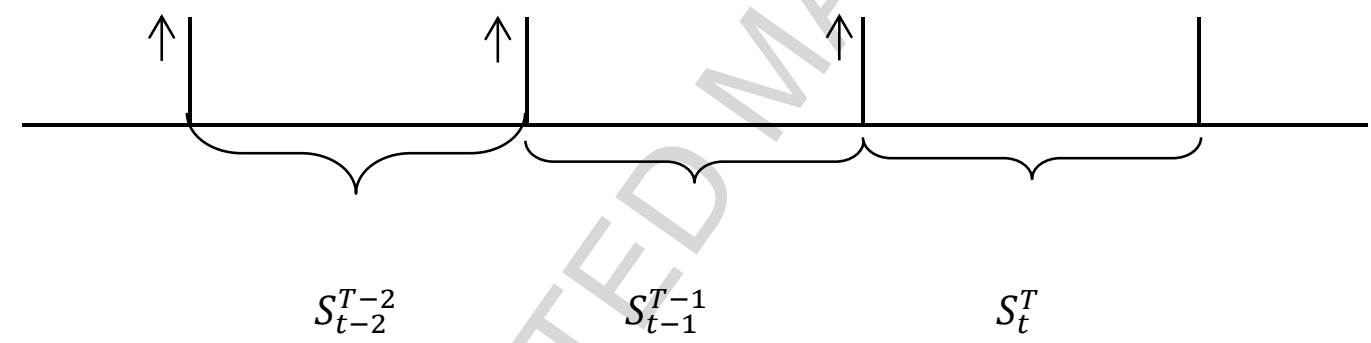

Fig. 8. The lag notation of futures and spot price series.

At this stage, it is worth also to clarify the definition of risk premium used in the literature, because many authors have used it loosely and inconsistently. Here we follow Weron and Zator (2014) and define the ex-ante risk premium at time $t$ to be realized at time $T$ as

$$
R P_{t, T}=E_{t}\left(S_{T}\right)-F_{t, T}
$$

and its negative value gives the futures premium as

$$
F P_{t, T}=-R P_{t, T}=F_{t, T}-E_{t}\left(S_{T}\right)
$$

For the ex-post premiums, the expected spot price $E_{t}\left(S_{T}\right)$ is replaced by the realized price $S_{T}$. To obtain the respective relative premiums, equations (3.3) and (3.4) are divided by the 
expected or realized spot prices at time $T$. Defined this way, the risk premium has similar interpretation as the market price of risk, which is commonly used in the financial literature (Weron and Zator, 2014). Some authors use the definitions above interchangeably, while some use the term bias (not every author uses logarithmic prices). Additionally, some make a distinction between them, but define the signs the opposite way.

In a widely cited paper Bessembinder and Lemmon (2002) examine optimal hedging and equilibrium futures pricing using daily data from April 1997 to July 2000 in the PJM (Pennsylvania, New Jersey and Maryland) and from April 1998 to July 2000 in the CALPX (California) markets based on the expectations model. However, their model implies that the ex-ante futures premium $F_{t, T}-E_{t}\left(S_{T}\right)$ depends also on the variance $\left(\operatorname{Var}\left(E_{t}\left(S_{T}\right)\right)\right)$ and skewness $\left(\operatorname{Skew}\left(E_{t}\left(S_{T}\right)\right)\right)$ of the expected spot prices, and in later studies their model has often been modified so that $E_{t}\left(S_{T}\right)$ is replaced by the realized spot price $S_{T}$. Hence, in this case the regression equation looks like

$$
F_{t, T}-S_{T}=b_{1}+b_{2} \operatorname{Var}\left(S_{T}\right)+b_{3} \operatorname{Skew}\left(S_{T}\right)+\varepsilon_{t}
$$

Furthermore, some authors have used the variance and skewness terms measured at time $t$ instead of delivery period $T$ as a proxy for expected variance and skewness.

For the part of Nordic market analyses, e.g. Redl et al. (2009) study the pricing of futures in the Nordpool and Central European (EEX) market using the data from 2003 to 2008. In addition to linking the year-ahead future prices to the year-ahead generation costs and current spot prices, they use an unrestricted vector autoregressive (VAR) model, and find that for the EEX peak load and Nord Pool base load contracts the lagged values of spot prices explain futures prices, while the opposite is not true, which would suggest the markets to be inefficient, and that the trading strategies of market participants could rely on the current spot prices. They also compute an ex-post average future premium for monthly contracts using the average futures prices during the last month of trading and prices from the last trading day, and find positive premiums for both the EEX and Nord Pool contracts on average. Additionally, they find evidence that the premiums are smaller in absolute terms for the last trading day than for the monthly average. They argue that this could indicate that the forecast error is a meaningful component of the premium as the market participants have more information available at the last trading day, and this is reflected in the futures prices. They 
also note that the sign of the premium varies over time, which they argue to provide further support for the presence of forecast errors.

Finally, Redl et al. (2009) test the above mentioned Bessembinder and Lemmon (2002) model and expand it to include factors that proxy for the supply and demand shocks in the delivery period. Their demand shock variable is the ratio between actual consumption and its long-term average in the relevant area. In the same manner, they construct the supply shock variable incorporating generation data for hydro and nuclear power. Their results from this part are somewhat mixed. In the EEX market they find partial support for the basic Bessembinder and Lemmon model, i.e., skewness of the spot prices explains the premium, but variance does not. From the Nordpool data they find no support for the model, and attribute this finding to the fundamentals of the Nordic market, like the high amount of flexible hydropower, which yields less skewed spot prices. They conclude that the positive future premiums arise from the risk assessments of market participants and unforeseen shocks may help to explain the forecast error, but still, market inefficiency cannot be ruled out.

The Nordic market is also studied in Lucia and Torro (2011), Gjolberg and Brattested (2011) as well as Weron and Zator (2014). Lucia and Torro (2012) investigate the futures premium of weekly system futures from 1998 to 2007. They find evidence of time-varying premiums that are positive on average, and vary over the year being the largest in winter and close to zero in summer. Moreover, they document that the relationship between unexpectedly low availability of hydro power and futures premium is positive. Although they find only partial support from 1998 to 2002 for the explicit Bessembinder and Lemmon (2002) model based on the spot price variance and skewness, they argue that the results confirm that tighter market conditions, which increase the risk of price spikes (i.e. skewness), impact the futures pricing.

Gjolberg and Brattested (2011) examine the "forecasting performance" of weekly Nordic system futures, and, unlike most authors, abstain from using the terms risk or futures premium. They document that the future prices exceed spot prices by (or the ex-post futures premium equals) $7.4 \%-9.3 \%$ on average on a monthly basis. They argue that for a number of reasons this cannot be explained solely based on risk considerations but also hints towards market inefficiency. They also note that the magnitude of error is suspiciously large and that the correlation of ex-post forecast error with different ex-post risk measures is zero. Moreover, they argue that the seasonality in forecast errors would indicate the presence of 
risk premium, as the demand risk varies seasonally. However, unlike Lucia and Torro (2012) they find that the forecast error does not exhibit clear seasonality. Finally, they interestingly discover that the forecast error has actually increased as the market has matured.

Weron and Zator (2014) study weekly futures in the Nordic market, and document negative futures premium for the front contract, and positive premiums for the contracts of three and six weeks from maturity. They extend some results of Lucia and Torro (2011) finding that the effect of unexpected availability of hydro power futures is not restricted only to low water reservoir levels. They document that the relationship between the risk (futures) premium and deviations in water reservoir from mean levels is positive (negative). Moreover, their regression results imply a weak positive relationship between the risk premium and unexpectedly high consumption. For the Bessembinder and Lemmon model they find no evidence that would support nor contradict it. Finally, they conclude that since fundamental factors can explain the premium to some extent, it more likely represents the price of risk than market inefficiency.

All the previously discussed studies define the risk or futures premium based on the realized (or expected) spot price during the delivery period, and the futures price based on the trading before the delivery period. Fleten and Hagen (2015) utilize a different approach. They view that the ex-post risk premium is hard to interpret. Furthermore, they argue that it measures the risk that does not need to be held. According to them the risk premium is determined by the hedging needs of retailers and producers as well as actions of traders, who have no incentive to hold futures over the delivery period. Even if they had, Fleten and Hagen argue that traders could offset the position with shorter maturity. Moreover, they highlight the same issue, as Fama and French (1987), namely the possible forecast error component of the ex-post risk premium. Therefore, they conclude that the methods based on the delivery price are inappropriate. Fleten and Hagen (2015) study the risk premium and its determinants overnight during the trading period using data from January 2002 to September 2012 from the German and Nordic markets. Similar to Gjolberg and Brattested (2011) they hypothesize that the producers hedge in longer-term, while retailers in short-term, as their volume forecasts become more accurate. They also find empirical support for this, because on average the risk premium for a contract is positive before it becomes a front contract (that nearest to maturity), and negative when it is a front contract. 
The overnight approach by Fleten and Hagen would indeed seem more reasonable than the one based on ex-post delivery price given their focus is on risk premium of speculators, who close their positions before the delivery period. Their research provides also further support for the relevance of the time-to-maturity in the pricing of electricity futures. However, in this study the emphasis is on the delivery period risk premium for the reasons mentioned in the introduction. Therefore, in the empirical section we will stick to the ex-post approach.

Kristiansen (2004a) examines EPADs preliminary. Using data from 2000 to 2002 he computes the average prices for various seasonal products ${ }^{1}$ during the trading period, and the respective realized spot prices. He finds that on average, Oslo (NO1) and Copenhagen (DK2) EPADs exhibit negative futures premium, while Stockholm (SE) and Helsinki (FI) positive. Moreover, Helsinki has clearly the highest positive premium. He attributes these results to the different market structures. For example, the Oslo area is dominated by lower spot prices and by risk-averse hydropower producers, who want to hedge their area price exposure. Conversely, one can conjecture that the spot prices and risk of price spikes are higher in Finland and, as a consequence, retailers are more risk-averse, while thermal producers are not that concerned about hedging the area price difference. Kristiansen (2004a) notes that the sample size is limited. Therefore, the inference should be treated cautiously.

Marckhoff and Wimschulte (2009) provide a more thorough study on the pricing of EPADs using methods common in the broader electricity market futures literature. They use data over the period of 2001 - 2006 and study also the implied area futures. Seasonal contracts constitute a significant share of the available data (quarterly and monthly products were introduced after 2003). Like Kristiansen (2004a), they use the futures prices from the whole trading period instead of the last trading day or shorter period. They find that the EPAD prices contain significant ex-post futures premium, whose sign and size varies between the different areas and delivery periods. Furthermore, the relationship between the ex-post futures premium and time-to-maturity is not uniform for EPADs, but clearly negative for the implied area futures. In the case of Finnish EPADs the effect of time-to-maturity seems to be negligible for monthly and yearly contracts, and only slightly positive for seasonal and quarterly contracts. Finally, they find that the skewness and variance of the underlying system and area prices have explanatory power over the ex-post futures premium of EPAD

\footnotetext{
${ }^{1}$ Back then there were seasonal products for spring, summer, autumn and winter, and EPADs were called CFDs.
} 
and implied area futures, which provides support for the Bessembinder and Lemmon (2002) model.

Similar to Kristiansen (2004a), Marckhoff and Wimschulte (2009) attribute the sign and size of futures premium to the different production structure and the resulting transmission congestion between different areas, i.e. asymmetric hedging needs of producer and consumers. They explain the negative relation between futures premium and time-to-maturity for the implied area futures the same way as Fleten and Hagen (2015) for the Nordic and German system futures, i.e., that the producers hedge for longer-term, while the retailers for short-term. For the Helsinki EPADs they compute the average futures premium for different contracts (yearly, quarterly, seasonal, and monthly) and find that they range from -1.34 $€ / \mathrm{MWh}$ to $2.79 € / \mathrm{MWh}$ and that positive premium occurs significantly more often than negative. They document also that the futures premium for the Finnish EPADs is higher for the winter contracts compared to the summer contracts, which could indicate asymmetric hedging demand between the seasons.

As mentioned earlier, the Bessembinder and Lemmon (2002) model has become the benchmark in the empirical electricity futures literature. The model can provide indirect evidence on the determinants of the premium, or more specifically, whether the premium can be explained by proxies for risk (variance and skewness). The model suggests that the ex-ante futures premium depends negatively on the variance and positively on the skewness of the expected spot prices. Using the notations given above, and the variance and skewness measures during time $T-1$ as a proxy for the expected variance and skewness ${ }^{2}$, for the purposes of analyzing the difference between the Finnish spot and the Nordic system prices, the regression model in our case would be

$$
F_{t}^{T-1, T}-S_{t}^{F I N-S Y S, T}=a+b_{1} \operatorname{VarS} S_{t-1}^{F I N-S Y S, T-1}+b_{2} \operatorname{Skew}\left(S_{t-1}^{F I N-S Y S, T-1}\right)+\varepsilon_{t},
$$

where $\varepsilon_{t}$ denotes the error term in the regression equation. Following the Marckhoff and Wimschulte (2009) model for the EPADs, and hence, using separately the skewness and variance measures of the system spot and Finnish area spot prices gives the regression model in the form

\footnotetext{
${ }^{2}$ Variance and skewness are computed from daily spot prices during month $\mathrm{T}-1$ (one month prior to the delivery period)
} 


$$
\begin{gathered}
F_{t}^{T-1, T}-S_{t}^{F I N-S Y S, T}=a+b_{1} \operatorname{Var}\left(S_{t-1}^{S Y S, T-1}\right)+b_{2} \operatorname{Skew}\left(S_{t-1}^{S Y S, T-1}\right)+c_{1} \operatorname{Var}\left(S_{t-1}^{F I N, T-1}\right) \\
+c_{2} \operatorname{Skew}\left(S_{t-1}^{F I N, T-1}\right)+\varepsilon_{t} .
\end{gathered}
$$

Marchhoff and Wimschulte (2009) note that a priori the coefficient on $\operatorname{Skew}\left(S_{t-1}^{F I N, T-1}\right)$ is expected to be positive, that is, price spikes in the previous month raise the Finnish EPADs prices and the futures premium if the market participants view that the possibility of further price spikes has increased, while the coefficient on $\operatorname{Skew}\left(S_{t-1}^{S Y S, T-1}\right)$ should be negative, and the coefficient on variances should be opposite to the signs of the coefficients on skewness.

In addition to separating the effects of market risk components as given above, previous studies have also considered the role of purely exogenous variables in these regression models. For example, following Weron and Zator (2014) the realized futures premium can also be regressed only against some exogenous variables (denoted for example $\mathrm{Z}$ and $\mathrm{X}$ in the case of two variables), so now a general form of the regression equation would be

$$
F_{t}^{T-1, T}-S_{t}^{F I N-S Y S, T}=a_{2}+b_{1} Z_{t-1}+b_{2} X_{t-1}+\varepsilon_{t}
$$

In our analysis the set of additional variables includes water reservoir level at time $t$-1, i.e., from the period before the delivery period to examine whether the abnormal demand and supply conditions affect the ex-ante premium (assuming rational expectations and a zero forecast error). However, we replace the consumption variable by the temperature as the electricity demand may have changed structurally over the years due to changes in industrial demand. Hence, the temperature variable provides a proxy for purely exogenous demand shocks as the electricity demand depends on the temperature during the heating season.

Following Weron and Zetor (2014), in our empirical analyses we decompose the observed water reservoir level variable to the seasonal (historical) and stochastic (deviation from mean) components, and a similar decomposition is applied to the temperature variable. The decomposition mitigates the problem that the water reservoir level (or temperature) exhibits strong seasonality, and hence, captures the effects of all omitted, seasonal variables, whereas the stochastic component reflects the real effect of the varying water reservoir level or temperature (Weron and Zetor, 2014). In this case the regression model reads as

$$
F_{t}^{T-1, T}-S_{t}^{F I N-S Y S, T}=a_{1}+b_{1} N O W_{t-1}+b_{2} d N O W_{t-1}+b_{3} d T E M P_{t-1}^{H E L}+\varepsilon_{t},
$$


where $N O W_{t-1}$ is the historical water reservoir level in Norway, $d N O W_{t-1}$ the water reservoir level deviation from the average in Norway and $d T E M P_{t-1}^{H E L}$ the temperature deviation from the historical average in Helsinki one month prior to the delivery period.

Only the water reservoir level variables from Norway were included since Norway has the largest hydro-reserves, and the water reservoir levels in Finland and Sweden are correlated with the Norwegian levels which would potentially lead to multicollinearity. Similarly, only the temperature in Helsinki is included as it has the highest impact on the Finnish area price difference, and temperatures in Oslo are correlated with temperatures in Helsinki. Finally, the historical temperature in Helsinki is omitted as it exhibits strong seasonality, which is already captured by the historical water reservoir level.

Weron and Zetor (2014) document that the below (above) -average water reservoir level increases (decreases) the futures premium on system futures. For the Finnish EPADs the impact should be the opposite, i.e., below-average water reservoir levels in Norway decrease the possibility of widening area price difference and hence decrease the futures premium. The temperature coefficient should in turn have a negative sign, i.e., below-average temperature in Helsinki increases the electricity demand in Finland and the risk of widening area price difference, which should increase the futures premium.

Finally, we also extend the regression model (3.9) by introducing a dummy variable Y2012 for the time period after 2011 (Y2012 = 1 after January 2012, and zero before that), since Russian imports decreased after the autumn of 2011. Hence, the largest version of the regression model based on purely exogenous variables is of the form

$$
\begin{aligned}
F_{t}^{T-1, T}-S_{t}^{F I N-S Y S, T} & =a_{1}+b_{1} N O W_{t-1}+b_{2} d N O W_{t-1} \\
& +b_{3} d T E M P_{t-1}^{H E L}+b_{4} Y 2012_{t}+\varepsilon_{t}
\end{aligned}
$$

Finally, in order to shed light on the dynamics of the Finnish EPADs vs. Finnish area price difference, we estimate a VAR system (similar to Redl et al., 2009). We also argue why their model may be incomplete and lead to misleading interpretation of the market inefficiency. Next we describe the details of the data and methods used in the empirical part of this study.

\section{Data and empirical methodology}


Monthly system and Finnish spot price (computed from hourly averages) data were retrieved from the Nord Pool web page for the period of January 2006 - January 2016. The area price difference $S_{t}^{F I N-S Y S_{T}}$ for each month $t$ was then obtained by subtracting the system price $S_{t}^{S Y S, T}$ from the Finnish price $S_{t}^{F I N, T}$ :

$$
S_{t}^{F I N-S Y S_{T}}=S_{t}^{F I N, T}-S_{t}^{S Y S, T}
$$

The monthly average prices for EPADs were computed as the average of daily closing prices of the last five trading days prior to the contract's delivery month $\mathrm{T}$ :

$$
F_{t}^{T-1, T}=\frac{1}{5} \sum_{n=-5}^{-1} F_{n, T}
$$

Thus, for example the futures price for delivery in October 2015 equals the average of daily closing prices of 09/30/2015,09/29/2015, 09/28/2015,09/25/2015 and 09/24/2015. The daily closing prices were obtained from a database of a third party that has received the data directly from Nasdaq. The ex-post futures premium PR for the delivery month $\mathrm{T}$ is then obtained as the difference between the futures price and the realized spot price difference defined in equations 4.1 and 4.2 :

$$
P R_{t}^{T}=F_{t}^{T-1, T}-S_{t}^{F I N-S Y S, T}
$$

Figure 9 depicts the area price difference, futures prices and futures premium for the analyzed time period.

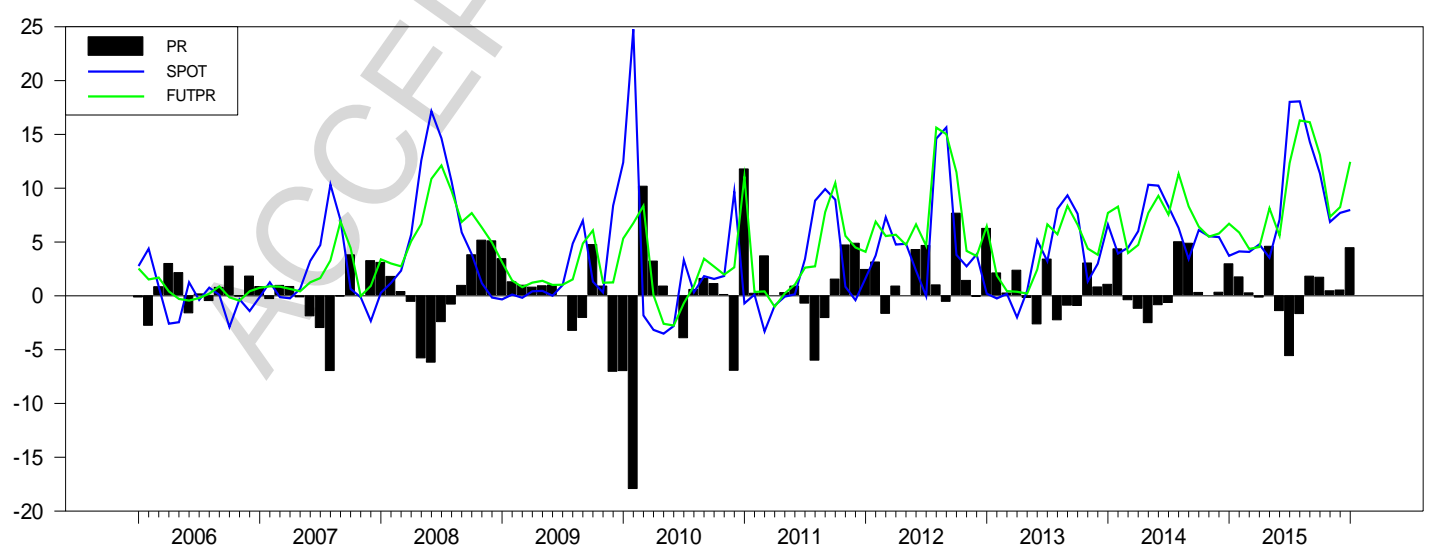

Fig. 9. Monthly area price difference (SPOT), respective futures prices and (FUTPR), and futures premium (PR) (€/MWh), between January 2006 - January 2016.

By visual inspection the futures prices seem to lag behind the realized spot price difference. The spike in the area price difference in February 2010 and the resulting large negative 
premium is notable. On the $22^{\text {nd }}$ of February 2010 the spot prices in Finland, Eastern Denmark and Sweden exceeded $1000 € / \mathrm{MWh}$ for several hours while the system price remained at $300 € / \mathrm{MWh}$ or below and the prices in Southern Norway and Western Denmark well below $100 € / M W h$. Similar spikes (for fewer hours) occurred also on the $17^{\text {th }}$ of December 2009 and $8^{\text {th }}$ of January 2010. The spikes in the winter are unprecedented because after excluding the December 2009, January 2010 and February 2010 observations, the maximum hourly area price difference in Finland has been $275.04 € / \mathrm{MWh}$ during the period from January 2006 to January 2016.

The spikes have been explained by below-average temperatures, low availability of Swedish nuclear power plants as well as outages from the transmission lines from Norway to Sweden, which increased the area prices in Sweden, Eastern Denmark and Finland (NordReg, 2011, 11-17). Moreover, hydropower availability has also been below-average (see Figure 10 below).

The following example describes the effect of the spikes to the Finnish area price difference and the resulting premium. Assuming that no such spikes would have occurred (i.e., that the transmission capacities would have been sufficient and all the area prices had been equal to the system price on those days), the realized Finnish area price differences on December 2009, January 2010 and February 2010 would have been $2.26 € / \mathrm{MWh}, 5.82 € / \mathrm{MWh}$ and $11.53 € / \mathrm{MWh}$, respectively, and the corresponding future premiums $-1.01 € / \mathrm{MWh}, 0.49$ $€ / \mathrm{MWh}$ and $-4.78 € / \mathrm{MWh}$.

Descriptive statistics for the area spot price difference, futures prices and premiums are presented in Table 2. As expected, the variance of the FINSYS spot price exceeds that of the monthly EPAD price, because electricity cannot be stored in the same way as numerous other commodities and the underlying spot price has to clear the market without inventories. The traded EPAD price has exceeded the area price difference price by $0.52 € / \mathrm{MWh}$. This result is in line with the findings of Spodniak et. al. (2014) who document an average premium of $0.15 € / \mathrm{MWh}$ for the Finnish monthly EPADs from 2004 to 2013, although they computed the average premium using the daily closing prices from the whole trading period. However, it is different from zero only at $88 \%$ confidence level. After excluding the observations from December 2009, January 2010 and February 2010, the average realized premium is almost $0.30 € / \mathrm{MWh}$ higher and different from zero at $1 \%$ risk level, while the variances of the area 
price difference and futures premium decrease. This emphasizes the effect of the spikes to the sample statistics.

Table 2.

Descriptive statistics of the primary variables. $* * *$ denotes statistically different from zero at $1 \%$ risk level.

\begin{tabular}{|c|c|c|c|c|c|c|c|}
\hline & $\mathrm{N}$ & Mean & Median & Variance & St. dev & Min & $\operatorname{Max}$ \\
\hline Monthly EPAD (€/MWh) & 121 & 4.53 & 4.18 & 16.81 & 4.10 & -2.76 & 16.3 \\
\hline FIN-SYS spot diff. ( $€ / M W h)$ & 121 & 4.01 & 3.22 & & 5.19 & -3.51 & 24.78 \\
\hline Futures premium $(€ / \mathrm{MWh})$ & 121 & 0.52 & 0.6 & & 3.6 & -18.03 & 11.79 \\
\hline \multicolumn{8}{|l|}{ Excl. 12/2009-2/2010 } \\
\hline Monthly EPAD (€/MWh) & 118 & 4.53 & 413 & 17.11 & 4.14 & -2.76 & 16.30 \\
\hline FIN-SYS spot diff. ( $€ / M W h)$ & 118 & & 2.88 & 23.09 & 4.81 & -3.51 & 18.07 \\
\hline Futures premium $(€ / \mathrm{MWh})$ & 118 & $0.81 * * *$ & 0.80 & 9.27 & 3.05 & -7.06 & 11.79 \\
\hline
\end{tabular}

As discussed earlier, asymmetric hedging needs and the fact that Finland is a net importer of electricity might well reflect the observed positive realized futures premium. However, the premium seems to vary between seasons. Table A1 in the Appendix exhibits descriptive statistics within seasons. Futures premium seems to be the highest in autumn and the lowest, even negative in summer. Furthermore, excluding again the spikes during the winter of 2009 - 2010, the premium becomes statistically significant also in winter exceeding that of autumn.

A possible reason for the seasonality in the premium is that electricity consumption varies seasonally which could cause the mismatch of hedging demand between natural sellers and buyers of Finnish EPADs to vary, too. Alternatively, the market participants' perceived risk is greater in autumn and winter than in summer leading to a positive premium during winter and autumn and negative in summer. Lucia and Torro (2011) document that the weekly Nordic futures have smaller futures premium in summer than in winter and attribute this to the seasonally varying electricity demand and the risk of price spikes. 
As the final part of our descriptive data analysis we performed the Dickey-Fuller and Phillips-Pearson unit root tests, that both gave the same conclusion that the two key interesting price series for our analysis are both stationary processes ${ }^{3}$. This is in line with the previous findings of e.g. Redl et al. (2009) who document that the monthly Nordic system futures and spot time series are stationary. Hence, we will continue our further analyses assuming that the data generating processes for the electricity market price series in our data set are stationary.

In addition to the actual price data, in the regression analysis we will also utilize some exogenous variables that have previously been found important in empirical electricity market research. As discussed earlier, the demand and supply conditions in the Nordic market are significantly affected by the climate and weather. For our study the time series of water reservoir level data (as a fraction of the total capacity) for Finland and Sweden were retrieved from Datastream, while both Datastream and Norwegian Water Resources and Energy Directorate provided the data for Norway ${ }^{4}$. Datastream provided daily data (calculated from weekly observations) from 11.1.1990 onwards for Sweden and Finland and from 3.1.2002 for Norway. For Norway the period between 11.1.1990 and 2.1.2002 was completed using the data from Norwegian Water Resources and Energy Directorate. Finally, the monthly values were computed by averaging the daily values.

Since the water reservoir levels vary seasonally, the market participants focus on the deviations from the historical average levels (Lucia and Torro, 2011). Therefore, following Lucia and Torro (2011) the historical monthly average values were computed for the sample period January 2006 - January 2016 for each month (with $\mathrm{T}=1, . ., 12$ ) and year (with $\mathrm{y}=$ $2006, . .2016$ ) so that for a given month in a given year the historical value was computed using the observations from 1990 to year y-1. Descriptive statistics of the observed values and deviations from the historical average are depicted in Table A2 in the Appendix.

The historical and observed values are plotted in Figure 10, where the seasonal pattern is evident. As Weron and Zator (2014) note, water inflows lead the reservoir levels; the largest inflows to the reservoirs occur in the spring and early summer as snow begins to melt. Vice

\footnotetext{
${ }^{3}$ All the statistical test results not reported in the text are available from the authors upon request.

${ }^{4}$ As mentioned earlier, because Sweden and Norway are important suppliers of hydropower electricity for Finland, we included also these data to our analyses.
} 
versa, the inflows decrease in the autumn as temperature decreases below zero. As a result, the water reservoir levels are the highest in autumn and lowest in the early spring.
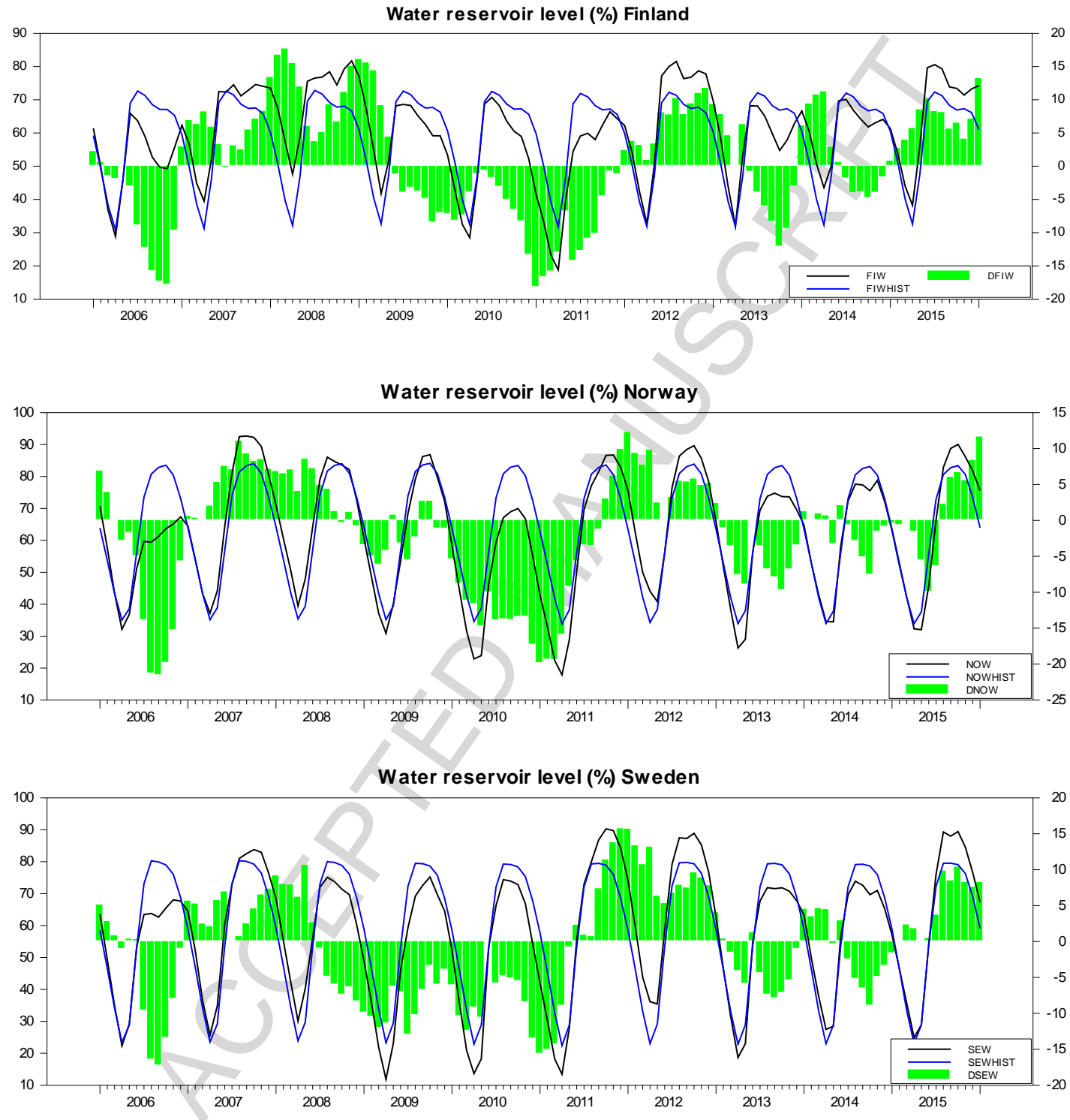

Fig.10. Observed (FIW, NOW and SEW) and historical (FIWHIST, NOWHIST and SEWHIST) water reservoir levels (left axis) and their differences (green bars, right axis) in Finland, Sweden and Norway from January 2006 to January 2016.

To our knowledge, previous research has not examined the effect of temperature to the futures bias directly. Redl et al. (2009) and Weron and Zator (2014) included electricity consumption indices to their models (as deviations from the long-term averages). As 
discussed above, electricity demand varies considerably within seasons in the Nordic countries, and Finland, too. Hence, temperature (being more stable than consumption over longer periods) deviations from the long-term average seem as a viable proxy for the demand shocks.

Monthly observed average temperatures for the period of January 1971 - January 2016 were obtained for Helsinki from the Finnish Meteorological Institute. Similar to water reservoir data, the historical monthly average values were computed for the sample period January 2006 - January 2016 for each month (with $\mathrm{T}=1, . ., 12$ ) and year (with $\mathrm{y}=2006, . .2016$ ) so that for a given month in a given year the historical value was computed using the observations from 1971 to year y-1. The historical and observed values are plotted in Figure 11.

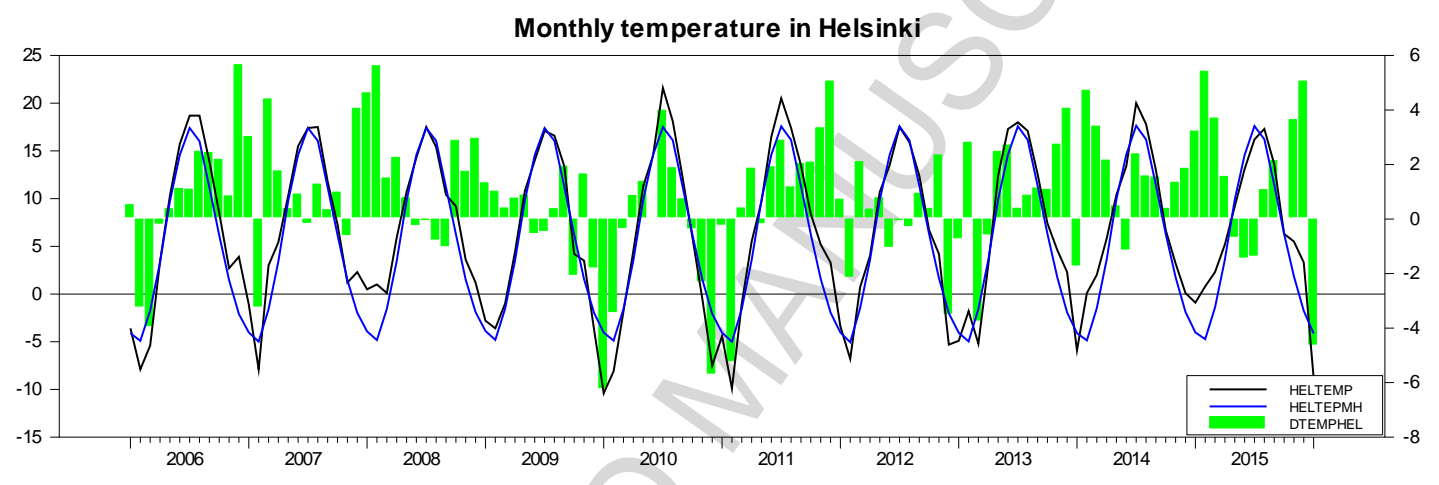

Fig. 11. Observed (HELTEMP) and historical (HELTEMPH) monthly temperatures (left axis) and their difference (DTEMPHEL, right axis) in Helsinki between January 2006 - January 2016.

In addition to the standard OLS regression analysis we will use the Vector Autoregressive (VAR) approach utilized also in some previous studies regarding the Nordic electricity market. For example Redl at al. (2009) have used an unrestricted VAR model to examine the relationship between the EEX peak load and Nord Pool base load contracts. We will use the same methodology for the Finnish area price difference and EPADs prices. We will also use Granger (1969) causality tests to analyze the dynamic relationships between the variables in our regression model and perform the standard impulse response and variance decomposition analyses based on the estimated VAR model to further to examine the dynamic behavior between the two relevant pricing series. Furthermore, to account for possible outliers in the cold winter of 2009 - 2010 with supply disruptions and the decrease in the Russian imports after 2012 we add two dummy variables to our model. Descriptions of all the variables used in the models are given in the next section where we report our empirical results. 
Here it is worth to mention that according to Redl et al. (2009), especially the concept of Granger causality can be linked to the analysis of market efficiency. For the Granger causality analysis, a general model between any two variables $(X, Y)$ can be written in the form

$$
\begin{aligned}
& Y_{t}=a_{1}+\sum_{j=i}^{m} b_{j} X_{t-j}+\sum_{j=i}^{m} c_{j} Y_{t-j}+\varepsilon_{Y, t} \\
& X_{t}=a_{2}+\sum_{j=i}^{m} d_{j} Y_{t-j}+\sum_{j=i}^{m} e_{j} X_{t-j}+\varepsilon_{X, t},
\end{aligned}
$$

where $a_{i}, b_{j}$ and $c_{j}$ are the parameters to be estimated, $m$ is the optimal lag length from the VAR model for variables $X$ and $Y$, and $\varepsilon_{X, t}, \varepsilon_{Y, t}$ are the error terms in the estimated equations. Variable $X_{t}$ Granger causes $Y_{t}$, if some of the coefficients $\mathrm{b}_{j}$ differ from zero. Similarly, $Y_{t}$ Granger causes $X_{t}$, if some of the coefficients $d_{j}$ are not zero. If both occur, there is a feedback relationship or bi-directional Granger causality between $\mathrm{X}_{\mathrm{t}}$ and $Y_{t}$. The model can also be extended to include a contemporaneous cross-term:

$$
\begin{aligned}
& Y_{t}=a_{1}+f_{1} X_{t}+\sum_{j=i}^{m} b_{j} X_{t-j}+\sum_{j=i}^{m} c_{j} Y_{t-j}+\varepsilon_{Y, t} \\
& X_{t}=a_{2}+f_{2} Y_{t}+\sum_{j=i}^{m} d_{j} Y_{t-j}+\sum_{j=i}^{m} e_{j} X_{t-j}+\varepsilon_{X, t} .
\end{aligned}
$$

Using equations (4.3) the VAR representation analogous to the Redl et al. (2009) model in our case can be written (applying the same notation we have used above and one lag of both price variables) as

$$
\begin{gathered}
F_{t}^{T-1, T}=a_{2}+d_{1} S_{t-1}^{F I N-S Y S, T-1}+e_{1} F_{t-1}^{T-2, T-1}+\varepsilon_{F, t} \\
S_{t}^{F I N-S Y S, T}=a_{1}+b_{1} F_{t-1}^{T-2, T-1}+c_{1} S_{t-1}^{F I N-S Y S, T-1}+\varepsilon_{S, t} .
\end{gathered}
$$

Redl et al. (2009) find that both the spot and futures prices can be explained by their lagged values. In addition, they find that the spot prices Granger cause the futures prices $\left(d_{1}\right.$ is significantly different from zero) but the futures prices do not Granger cause the spot prices ( $b_{1}$ is not significantly different from zero). Hence, they conclude that "spot prices in the trading period of the forward contracts are relevant for the price formation of the forwards whereas the opposite is not true" and therefore argue that "there is strong evidence that the predictive power of the forward price is weak" (Redl et al., 2009, 361).

Because these findings actually speak for the possibility of inefficiencies in the relevant markets, it is worth to take a closer look at their results. In fact, their conclusions can be 
criticized at least from two points of view. First, notice the time notation for the futures term in equation $4.5 \mathrm{~b}$. The term $F_{t-1}^{T-2, T-1}$ refers to the price of futures contract, whose delivery period is $T-1$. Hence, it should be of no surprise that it does not explain well the spot price at $T$. A more fruitful approach will be to replace $F_{t-1}^{T-2, T-1}$ with an "instantaneous" term $F_{t}^{T-1, T}$ so that for this stage the set of equations will be:

$$
\begin{gathered}
F_{t}^{T-1, T}=a_{2}+d_{1} S_{t-1}^{F I N-S Y S, T-1}+e_{1} F_{t-1}^{T-2, T-1}+\varepsilon_{F, t} \\
S_{t}^{F I N-S Y S, T}=a_{1}+b_{1} F_{t}^{T-1, T}+c_{1} S_{t-1}^{F I N-S Y S, T-1}+\varepsilon_{S, t}
\end{gathered}
$$

Second, Redl et al. (2009) argue that their results imply that the futures market might not be efficient, since spot prices in the trading period affect futures (whose delivery period is the next month) prices. This would certainly be a valid conclusion if the spot prices of the consequent months would not be strongly correlated. However, spot prices are autocorrelated as is evident from the significance of the parameter $c_{1}$ in their results. Therefore, it is not completely surprising that the market participants' expectations (futures price) of the next month's spot price are affected by the spot price in the preceding month. Nevertheless, in an efficient market one should a priori expect the coefficient $d_{1}$ to be less significant and further away from unity than the coefficient $b_{1^{*}}$.

All the previous studies give us the basis to discuss own results based on the most recent data. Next we will report the results from our empirical analyses utilizing the Nordic and Finnish electricity market data from the period of January 2006 - January 2016.

\section{Empirical results}

In Table 3 we report the empirical results based on the regression models (3.6.) and (3.7), that are comparable to the much cited Bessembinder and Lemmon (2002) results, but for the Nordic and Finnish data in our case. Based on the interpretation of the constant term in the reported regression results, and especially after controlling for the effects of extreme winter of 2009 - 2010 in model (3.7), where also the effects of risk measures are separated to the effects from the Finnish spot market price risk and the Nordic system price risk, the average excess premium is positive and statistically significantly different from zero at $1 \%$ (for the whole sample and) and $10 \%$ (for the sample excluding the hard winter of $2009-2010$ ) level 
in specification (3.6) and at least at $5 \%$ level in specification (3.7). Moreover, coefficients on the second moment components of the price distributions (for both the Finnish area price and the Nordic system price), i.e., variances are insignificant. Typical to the regression analyses for derivative markets price data without any dynamic structure in the models, the $\mathrm{R}^{2}$-values of the regressions are very low ${ }^{5}$. A possible reason for our results favoring perhaps not so strong role for the risk components as in the earlier studies might be that the market participants in the Finnish vs. Nordic markets seem to view risks as temporary and not overbid the next month's futures price despite the elevated risk in the previous period. Hence, it seems that risk considerations (at least measured by skewness, variance or kurtosis of the daily spot prices) are not so meaningful for the pricing of monthly Finnish EPADs. It should also be noted that Marchhoff and Wimschulte (2009) aggregated the futures premium of all the EPADs when they obtained their results supporting the Bessembinder and Lemmon model. Thus their results are not directly comparable to ours.

Table 3.

Results from the OLS regressions of equations (3.6) and (3.7). We used the Newey-West correction to obtain the autocorrelation and heteroscedasticity consistent standard errors in our estimations, and $t$-statistics for the null of zero coefficients on the variables are reported in parenthesis. The full sample is from January 2006 to January 2016, $n$ denotes the number of observations, $\mathrm{R}^{2}$ the coefficient of determination from the regression, and $*, * *$ and $* * *$ the significance of parameter estimates at 10,5 and $1 \%$ risk levels, respectively.

Equation (3.6) is $F_{t}^{T-1, T}-S_{t}^{F I N-S Y S, T}=a+b_{1} \operatorname{Var}\left(S_{t-1}^{F I N-S Y S, T-1}\right)+b_{2} \operatorname{Skew}\left(S_{t-1}^{F I N-S Y S, T-1}\right)+\varepsilon_{t}$, and Equation (3.7) is

$$
F_{t}^{T-1, T}-S_{t}^{F I N-S Y S, T}=a+b_{1} \operatorname{Var}\left(S_{t-1}^{S Y S, T-1}\right)+b_{2} \operatorname{Skew}\left(S_{t-1}^{S Y S, T-1}\right)+c_{1} \operatorname{Var}\left(S_{t-1}^{F I N, T-1}\right)+c_{2} \operatorname{Skew}\left(S_{t-1}^{F I N, T-1}\right)+\varepsilon_{t}
$$

\begin{tabular}{|c|c|c|c|c|}
\hline \multirow{2}{*}{ arameters } &  & ion (3.6) & \multicolumn{2}{|c|}{ Equation (3.7) } \\
\hline & Whole sample & Excl. 12/2009 -3/2010 & Whole sample & Excl. 12/2009-3(2010 \\
\hline$a$ & $\begin{array}{l}0.68 * * * \\
(2.56)\end{array}$ & $\begin{array}{l}0.55^{*} \\
(1.81)\end{array}$ & $\begin{array}{l}0.73 * * * \\
(2.57)\end{array}$ & $\begin{array}{l}0.83 * * \\
(2.27)\end{array}$ \\
\hline$b_{1}$ & $\begin{array}{c}0.00 \\
(0.78)\end{array}$ & $\begin{array}{c}0.01 \\
(0.91)\end{array}$ & $\begin{array}{l}-0.00 \\
(0.46)\end{array}$ & $\begin{array}{l}-0.00 \\
(0.25)\end{array}$ \\
\hline$b_{2}$ & $\begin{array}{c}-0.40 \\
(-1.69)\end{array}$ & $\begin{array}{c}-0.16 \\
(-0.97)\end{array}$ & $\begin{array}{c}0.60 \\
(1.77)\end{array}$ & $\begin{array}{l}0.67 * * \\
(2.13)\end{array}$ \\
\hline$c_{1}$ & - & - & $\begin{array}{c}0.00 \\
(0.31)\end{array}$ & $\begin{array}{c}-0.00 \\
(-0.24)\end{array}$ \\
\hline$c_{2}$ & - & - & $\begin{array}{l}-0.80 * \\
(-1.75) \\
\end{array}$ & $\begin{array}{c}-0.25 \\
(-0.60) \\
\end{array}$ \\
\hline $\begin{array}{c}\text { Statistics } \\
n \\
R^{2} \\
\end{array}$ & $\begin{array}{l}121 \\
0.02\end{array}$ & $\begin{array}{l}116 \\
0.00\end{array}$ & $\begin{array}{c}121 \\
0.00\end{array}$ & $\begin{array}{l}116 \\
0.00\end{array}$ \\
\hline
\end{tabular}

\footnotetext{
${ }^{5}$ For the sake of robustness regarding the risk measures we also regressed the premium against the measure of kurtosis, but in all cases the coefficients on the kurtosis measures were statistically insignificant.
} 
When regressing the premium to the fundamental variables affecting the demand and supply of electricity, we find that the average excess premium (i.e., the constant term in the regressions) is not statistically significantly different form zero anymore, so the arbitrage possibilities would seem to vanish from this market. In addition, according to our results reported in Table 4, contrary to e.g. the findings of Weron and Zetor (2014) only the seasonal component of the water reservoir variable $N O W_{t-1}$ seems to be statistically significant in our data, and especially after controlling for the hard winter of $2009-2010$, it is significant even at the $1 \%$ risk level, and increases the premium. It captures all the seasonal effects so that the higher is the absolute water reservoir level, the higher is the futures premium. This is consistent with the fact that the premium has been highest during autumns and lowest during summers as presented in section 4 .

\section{Table 4.}

Results from the OLS regressions of equations (3.9) and (3.10). We used the Newey-West correction to obtain the autocorrelation and heteroscedasticity consistent standard errors in our estimations, and $t$-statistics for the null of zero coefficients on the variables are reported in parenthesis. The full sample is from January 2006 to January 2016, $n$ denotes the number of observations, $\mathrm{R}^{2}$ the coefficient of determination from the regression, and $*, * *$ and $* * *$ the significance of parameter estimates at 10,5 and $1 \%$ risk levels, respectively. Equation (3.10) is $F_{t}^{T-1, T}-S_{t}^{F I N-S Y S, T}=a_{1}+b_{1} N O W_{t-1}+b_{2} d N O W_{t-1}+b_{3} d T E M P_{t-1}^{H E L}+b_{4} Y 2012_{t}+\varepsilon_{t}$, and equation (3.9) is the same without the Russian import dummy Y2012.

\begin{tabular}{c|cccc}
\multirow{2}{*}{ Parameters } & \multicolumn{3}{|c}{ Equation (3.9) } & \multicolumn{2}{c}{ Equation (3.10) } \\
\hline & Whole sample & Excl. 12/2009 $-3 / 2010$ & Whole sample & Excl. 12/2009-3/2010 \\
\hline$a$ & -1.26 & -1.52 & $-1.66^{*}$ & $-1.81^{* *}$ \\
& $(-1.29)$ & $(-1.73)$ & $(-1.69)$ & $(-2.03)$ \\
$b_{1}$ & $0.03^{*}$ & $0.04^{* * *}$ & $0.03^{*}$ & $0.04^{* *}$ \\
& $(1.74)$ & $(2.62)$ & $(1.76)$ & $(2.63)$ \\
$b_{2}$ & 0.00 & 0.01 & 0.01 & 0.00 \\
& $(0.00)$ & $(0.28)$ & $(0.35)$ & $(0.03)$ \\
$b_{3}$ & 0.12 & 0.09 & 0.10 & -0.09 \\
& $(0.41)$ & $(0.54)$ & $(0.37)$ & $(-0.57)$ \\
$b_{4}$ & - & - & $0.95^{*}$ & 0.63 \\
& & & $(1.64)$ & $(1.17)$ \\
\hline Statistics & & & & \\
$n$ & 120 & 116 & 120 & 116 \\
$R^{2}$ & 0.00 & 0.03 & 0.004 & 0.03 \\
\hline
\end{tabular}

The results from the regression taking into account the period after 2012 are shown in the right-hand side (the second and fourth) columns of Table 4. There we see that the decrease of Russian imports from the autumn of 2011 onwards has a statistically significant (at 10\% level) effect, and the coefficient on the dummy variable implies that the premium has been $0.95 € / \mathrm{MWh}$ higher after 2012 due to this effect. The result is intuitive as the Russian 
importers might have been natural sellers of Finnish EPADs and as imports from Sweden have increased, the "deficit" between natural buyers and sellers of Finnish EPADs has widened further. Based on the observed very low $R^{2}$ values it is obvious that also the regression analysis based on equations (3.9) and (3.10) may still suffer from an omitted variable bias. Important variables that may affect market participants' perception of risk are for example the expected availability of transmission lines from Sweden to Finland, and the availability of nuclear power in Finland. Both of them affect the area price risk in Finland. Unfortunately, data on them were not available, and hence, they could not be included in the regression. It seems obvious that we are not able to find very strong empirical support for many of the previous studies from our data set based on the standard regression model approach. However, it is also obvious that there are arbitrage opportunities in the financial market segment of the Finnish electricity markets, because the excess futures premium is positive and statistically significant in every specification considered so far. This speaks for the possibility that the Finnish EPADs market might not be efficient. Hence, as the final stage of our study we report the results from the VAR analysis that should give us more specific information about the possible inefficiencies, i.e., dynamic connections between the relevant variables in the pricing of Finnish EPADs. Optimal lag lengths for our VAR analyses were chosen based on using the minimum values for the Akaike and Schwarz information criteria, and they suggested that the proper lag length is two in our data set. However, for comparison we also ran the regressions with a lag length of one to compare the results to those of Redl et al. (2009).The results for the basic VAR model are presented in Table 5, where we report the actual regression coefficients from the VAR analysis enabling to reveal the actual dynamic dependencies between the examined price series. 
Table 5.

Results from the VAR analysis. In the left panel we report the results from a VAR(2) model and in the right panel from a VAR(1) model. For the case with two lags the model is

$y_{t}=\left[\begin{array}{c}S_{t}^{F I N-S Y S, T} \\ F_{t}^{T-1, T}\end{array}\right]=\left[\begin{array}{l}a_{10} \\ a_{20}\end{array}\right]+A_{1}\left[\begin{array}{c}S_{t-1}^{F I N-S Y S, T-1} \\ F_{t-1}^{T-2, T-1}\end{array}\right]+A_{2}\left[\begin{array}{c}S_{t-2}^{F I N-S Y S, T-2} \\ F_{t-2}^{T-3, T-2}\end{array}\right]+\varepsilon_{t}$, where $A_{1}=\left[\begin{array}{ll}\gamma_{11} & \gamma_{12} \\ \gamma_{21} & \gamma_{22}\end{array}\right]$ and $A_{2}=$ $\left[\begin{array}{ll}\delta_{11} & \delta_{12} \\ \delta_{21} & \delta_{22}\end{array}\right]$, whereas for the VAR(1) model matrix $A_{2}$ and the corresponding variable vector are skipped. $S_{t}^{F I N-S Y S, T}$ denotes the Finnish EPAD (spot) price and $F_{t}^{T-1, T}$ denotes the futures price. In the lower panel we report the $F$-test values for testing the null of no Granger causality between the analyzed variables. $t$-statistics for testing the significance of the individual parameters estimates in the VAR models are given in parenthesis $(*, * *$ and $* * *$ refer to the significance of parameter estimates at 10,5 and $1 \%$ risk levels, respectively), and $P$ values from the $F$-test for Granger causality are in square brackets. D-W statistics denotes Durbin-Watson statistics for the autocorrelation in the residuals of the model and $N$ refers to the number of observations.

\begin{tabular}{|c|c|c|c|c|}
\hline \multirow[b]{2}{*}{ Expl. variables / Dep. variable } & \multicolumn{2}{|c|}{$\operatorname{VAR}(2)$} & \multicolumn{2}{|c|}{$\operatorname{VAR}(1)$} \\
\hline & $S_{t}^{F I N-S Y S, T}$ & $F_{t}^{T-1, T}$ & $S_{t}^{F I N-S Y S, T}$ & $F_{t}^{T-1, T}$ \\
\hline Constant & $1.26^{* *}$ & $0.98 * * *$ & $1.40 * *$ & $1.23 * * *$ \\
\hline$S^{F I N-S Y S, T-1}$ & $(2.15)$ & $\begin{array}{c}(3.19) \\
0.48 * * *\end{array}$ & $\begin{array}{c}(2.51) \\
0.59 * * *\end{array}$ & $\begin{array}{c}(4.08) \\
0.45 * * *\end{array}$ \\
\hline $\mathrm{s}_{t-1}$ & $0.60^{* * *}(5.75$ & $\begin{array}{c}0.48 \\
(8.68)\end{array}$ & $(5.65)$ & $(7.94)$ \\
\hline$S_{t-2}^{F I N-S Y S, T-2}$ & $-0.31 * *$ & $-0.260^{* * *}$ & - & - \\
\hline$F_{t-1}^{T-2, T-1}$ & $0.44 * *$ & $0.52 * * *$ & 0.058 & $0.34 * * *$ \\
\hline & $(2.21)$ & (5.04) & $(0.44)$ & $(4.69)$ \\
\hline$F_{t-2}^{T-3, T-2}$ & $\begin{array}{c}-0.09 \\
(-0.61)\end{array}$ & $\begin{array}{c}0.08 \\
(1.05) \\
\end{array}$ & - & - \\
\hline$D-W$ statistics & 2.01 & 2.01 & 1.77 & 1.56 \\
\hline$N$ & 119 & 119 & 119 & 119 \\
\hline Granger causal & & & & \\
\hline $\mathrm{S}$ & 17.82 & 41.20 & 31.96 & 63.11 \\
\hline & {$[0.00]$} & {$[0.00]$} & {$[0.00]$} & {$[0.00]$} \\
\hline $\mathrm{F}$ & 2.52 & 19.01 & 0.19 & 21.96 \\
\hline  & {$[0.09]$} & {$[0.00]$} & {$[0.66]$} & {$[0.00]$} \\
\hline
\end{tabular}

The VAR results have multiple implications. First, they reveal the autocorrelation structure of both of the price series and it seems that the own lagged values explain the current values of both series. For both the spot and futures price series in the VAR(2) model both lags of the spot prices are significant whereas only the once lagged futures prices seem to have an effect on the current values of spot prices (at $5 \%$ risk level). This is confirmed by the F-tests on Granger causality. Both in the VAR(2) and VAR(1) models especially the first lag of spot 
prices is significant in explaining the current futures prices. This is also confirmed by the Ftests, which indicate that the spot prices Granger-cause the futures prices, but the futures prices do not Granger-cause the spot prices (even though this is not the case at $10 \%$ risk level in the case of VAR(2) model). This implies that the previous spot price affects the market's expectation of the next month's spot price, that is, the futures price for the next month's delivery period, and provides evidence that the futures pricing may be inefficient at least to some extent. However, it is not possible to state that the market is completely inefficient although the past spot prices help explain the futures prices. As the consecutive area spot differences are serially correlated, the market is not totally irrational when it resorts to the previous realized spot price difference in estimating the next month's area price difference

Because in our previous results the extreme winter conditions in 2009 - 2010 and also the reduction of Russian imports from 2012 onwards proved to have role to play in the analysis of pricing behavior in the Finnish markets, for the sake of robustness of our results, we next estimated the VAR models with time dummies to control for these effects. The results are presented in Table 6 and do not change much from the results given above, although they indicate the clear significance of the respective periods, too. However, here we find that the hard winter of 2009 - 2010 has had an increasing effect specifically on the spot prices but not on the futures prices at all, whereas the reduction of Russian imports has had a statistically significant and positive, i.e. increasing effect both on the spot and futures prices, and the effect has been almost of same magnitude in both markets. 
Table 6.

Results from the VAR-X analysis, where the effects of winter 2009 - 2010 and the reduction in Russian imports from 2012 onwards have been taken account. For the case with two lags the model is now

$$
\left[\begin{array}{c}
S_{t}^{F I N-S Y S, T} \\
F_{t}^{T-1, T}
\end{array}\right]=\left[\begin{array}{l}
a_{10} \\
a_{20}
\end{array}\right]+A_{1}\left[\begin{array}{c}
S_{t-1}^{F I N-S Y S, T-1} \\
F_{t-1}^{T-2, T-1}
\end{array}\right]+A_{2}\left[\begin{array}{c}
S_{t-2}^{F I N-S Y S, T-2} \\
F_{t-2}^{T-3, T-2}
\end{array}\right]+\left[\begin{array}{l}
b_{11} \\
b_{12}
\end{array}\right] Y 12+\left[\begin{array}{c}
c_{11} \\
c_{12}
\end{array}\right] W 0910+\varepsilon_{t}
$$

where in addition to the notations given in Table 5, Y12 refers to the dummy variable describing the reduction of Russian imports from 2012 onwards ( $Y 12=1$ after January 2012, and zero before that), and W0910 is the dummy variable for the winter $2009-2010$ ( $W 0910=1$ from 12/2009 to 3/2010 and zero otherwise). For all the other notations see Table 5 .

\begin{tabular}{|c|c|c|c|c|}
\hline \multirow[b]{2}{*}{ Expl. variables / Dep. variable } & \multicolumn{2}{|c|}{$\operatorname{VAR}(2)$} & \multicolumn{2}{|c|}{ VAR(1) } \\
\hline & $S_{t}^{F I N-S Y S, T}$ & $F_{t}^{T-1, T}$ & $S_{t}^{F I N-S Y S, T}$ & $F_{t}^{T-1, T}$ \\
\hline Constant & $\begin{array}{c}0.71 \\
(131)\end{array}$ & $0.91 * * *$ & 0.708 & $0.98 * * *$ \\
\hline \multicolumn{5}{|l|}{$S_{t-1}^{F I N-S Y S, T-1}$} \\
\hline t-1 & $0.51 * * *(5.27)$ & $(9.01)$ & $0.519 * * *(5.30)$ & $0.481 * * *(8.81)$ \\
\hline$S_{t-2}^{F I N-S Y S, T-2}$ & $\begin{array}{c}-0.25 * * \\
(-203)\end{array}$ & $\begin{array}{l}-0.18 * * \\
(-260)\end{array}$ & - & - \\
\hline$F_{t-1}^{T-2, T-1}$ & $0.46 * *$ & $0.40^{* * *}$ & 0.041 & $0.198 * *$ \\
\hline$F_{t-2}^{T-3, T-2}$ & -018 & 0.00 & $\begin{array}{c}(0.30) \\
-\end{array}$ & $\begin{array}{c}(2.59) \\
-\end{array}$ \\
\hline \multirow[t]{2}{*}{$Y 12$} & $1.76^{* *}$ & $1.57 * *$ & $1.942 * *$ & $1.90^{* * *}$ \\
\hline & (2.08) & $(3.30)$ & $(2.42)$ & $(4.24)$ \\
\hline \multirow[t]{2}{*}{ W0910 } & $11.05 * * *$ & -0.34 & & -0.440 \\
\hline & $(5.05)$ & $(-0.28)$ & $10.720 * *(2.25)$ & $(-0.34)$ \\
\hline \multirow{2}{*}{$\begin{array}{c}D-W \text { statistics } \\
N\end{array}$} & 1.85 & 1.97 & 1.61 & 1.57 \\
\hline & 119 & 119 & 119 & 119 \\
\hline \multicolumn{5}{|l|}{ Granger causality } \\
\hline S & 14.97 & 42.06 & 28.11 & 77.69 \\
\hline & [0.00] & {$[0.00]$} & [0.00] & [0.00] \\
\hline $\mathrm{F}$ & 3.10 & 7.39 & 0.09 & 6.72 \\
\hline & [0.05] & {$[0.00]$} & [0.76] & [0.01] \\
\hline
\end{tabular}

As discussed in section 4 (see equations (4.6) and the discussion therein), inference based on the traditional reduced form VAR setup might be ambiguous to some extent owing to the fact that it does not include the contemporary futures price term, and because the spot price and futures prices for the same delivery period constitute perhaps the most interesting relationship between the two series, it should actually be taken into account in the VAR model. Hence, as the final step, to shed more light on the pricing dynamics we regressed the spot price against 
its own lags, and lagged and contemporary values of the futures price series. The results from this stage are presented in Table 7.

Table 7.

Regression results for the spot price equation containing only the once lagged values of spot EPAD prices and contemporaneous values of the futures prices, i.e., the regression equation is $S_{t}^{F I N-S Y S, T}=a_{1}+b_{1} F_{t}^{T-1, T}+$ $c_{1} S_{t-1}^{F I N-S Y S, T-1}+\varepsilon_{t}$ (Model 1), and for the case involving two lags of the spot prices and contemporaneous values and one lag of futures prices, the corresponding equation is $S_{t}^{F I N-S Y S, T}=a_{1}+b_{1} F_{t}^{T-1, T}+c_{1} S_{t-1}^{F I N-S Y S, T-1}+d_{1} F_{t-1}^{T-2,-T-1}+e_{1} S_{t-2}^{F I N-S Y S, T-2}+\varepsilon_{t}($ Model 2). For all the notations see Tables 4 - 6 .

\begin{tabular}{c|c|c}
\hline & Model 1 & Model 2 \\
Expl. variables / Dep. variable & $S_{t}^{\text {FIN-SYS,T }}$ & $S_{t}^{\text {FIN-SYS,T }}$ \\
\hline Constant & -0.07 & 0.19 \\
& $(-0.14)$ & $(0.37)$ \\
$F_{t}^{T-1, T}$ & $0.81^{* * *}$ & $0.88^{* * *}$ \\
$S_{t-1}^{F I N-S Y S, T-1}$ & $(5.83)$ & $(5.58)$ \\
$F_{t-1}^{T-2, T-1}$ & 0.11 & $0.20^{*}$ \\
$S_{t-2}^{F I N-S Y S, T-2}$ & $(0.99)$ & $(1.74)$ \\
& - & -0.12 \\
$\mathrm{R}^{2}$ & $-0.63)$ \\
$N$ & - & -0.12 \\
Granger causality & 0.52 & $(-1.07)$ \\
$\mathrm{S}$ & 120 & 0.53 \\
$\mathrm{~F}$ & - & 119 \\
\hline & 14.56 & - \\
& {$[0.00]$} & 18.51 \\
& & {$[0.00]$} \\
\hline
\end{tabular}

Results from both of these modified regression equations indicate that the contemporary futures price has significant predictive power over the spot price difference for the respective delivery period. From the results reported for Model 2, i.e. the one containing also the lagged values of the futures prices, we see that actually introducing the contemporaneous values of the futures price series to the model absorbs all the explanatory power from the lagged futures prices that we observed in the results reported in Table 6. Hence, at least in terms of statistical significance, our argument in favor of using the contemporaneous values in pricing the Finnish electricity market EPADs seems strongly valid. The F-tests on Granger causality confirm that when the series for contemporary futures price is included to the model, the futures prices Granger cause the spot price. This mitigates the relevance of our earlier results 
that suggested market inefficiency based on the role of past prices in evaluating the futures prices for the next period.

In conclusion, there is a clear bi-directional causality between the futures and spot prices in the Finnish market. This is illustrated in Figure 12. On one hand, $S_{t-1}^{F I N-S Y S, T-1}$ (the previous spot price) influences $F_{t}^{T-1, T}$ (the contemporaneous futures price, or market's expectation for the spot price in next month's delivery period), and on the other hand $F_{t}^{T-1, T}$ also has predictive power over $S_{t}^{F I N-S Y S, T}$ (the contemporaneous spot price). The connection between them seems to be based on the fact that the spot prices are serially correlated. This implies that the market's expectation of the next month's spot price may be at least partially influenced by the spot price in the previous period, and at the same time, the futures market need not be as inefficient as would seem at the first glance.

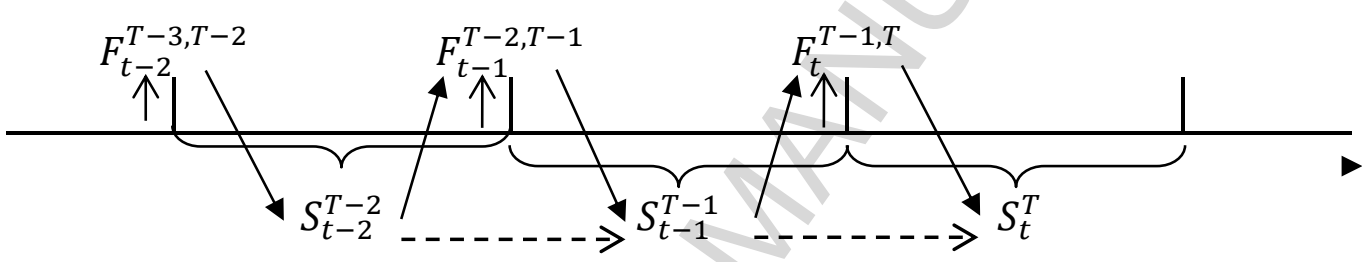

Fig. 12. A stylized describing the bi-directional relationship between the spot and futures prices.

\section{Conclusions and suggestions for further research}

In recent years, the electricity market spot prices have been systematically higher in Finland than in other Nordic countries. This has exposed the Finnish market participants to significant basis risks when using only the Nordic system futures for hedging. We examined the pricing of Finnish EPADs that are used to hedge the price difference between the Finnish spot price and the Nordic system price. More specifically, we analyzed whether the monthly EPADs prices are biased estimates of the future area price difference and whether the bias can be attributed to market inefficiency or a risk premium.

Our results imply that on average the futures prices before the delivery period have exceeded the Finnish area spot price difference in the respective delivery period. This result is clearly intuitive as Finland is a net importer of electricity and as a consequence, there are less natural sellers of Finnish EPADs than buyers and since the area price difference risk is biased 
upwards. The positive bias is also in line with the results from Redl et al. (2009) and Lucia and Torro (2011) from different electricity markets.

The bias seems to vary between seasons, and is significantly different from zero only when excluding the extreme observations of winter 2009 - 2010 from the sample. Again, Lucia and Torro (2011) obtained a similar result for the weekly Nordic system futures. A possible reason for the seasonality might be that electricity consumption varies seasonally which might cause the systematic mismatch of hedging demand between natural sellers and buyers of Finnish EPADs to vary also. Alternatively, the market participant's perceived risk may be greater in autumn and winter than in summer leading to positive premium during winter and autumn and negative in summer.

Both risk considerations and market inefficiency seem to explain the bias. However, we document little support for the findings of previous studies, that have linked the bias to abnormal electricity supply and demand conditions (Weron and Zator, 2014) or different kind of risk proxies derived from realized spot price distributions in the preceding period (Marchhoff and Wimschulte, 2009). Instead, one of our strongest results is that the bias has increased after 2012. This could be attributed to the decrease in Russian imports, which may have widened the imbalance between the electricity consumers and generators that naturally hedge the Finnish area price leading to a positive futures premium in the futures market. The fact that the bias, similar to the electricity consumption pattern, exhibits seasonality, might also suggest that it may to some extent be explained by risk considerations.

Finally, we document a strong bi-directional causality relationship between the Finnish area price difference and the EPADs, which could hint that the bias may at least partly stem from a somewhat inefficient, backward-looking futures market that utilizes the realized area spot price difference to forecast the next period's area spot price difference. Redl et al. (2009) found similar results for the earlier data on Nordic system and EEX futures. The bidirectional relationship might also contribute to the seasonality of the futures premium as the area price difference exhibits also some seasonality. However, due to the fact that the area spot price differences are serially correlated it is impossible to state that the futures market is completely inefficient even when it incorporates past information to futures prices for the next's period price.

The results show that the Finnish market participants should pay attention to their area price hedging policies and timing as the futures market has somewhat positive bias that varies 
within seasons, and since the market seems to clearly be backward-looking. Due to the fact that this study has solely focused on the Finnish EPADs and monthly contracts and the EPADs are unique to each bidding area which by themselves have unique fundamentals, it is unclear how widely the results can be generalized to other bidding areas. However, it seems reasonable to assume that they may well exhibit similar peculiarities for example in terms of the past spot prices affecting the futures market.

Our results give a strong indication that the EPAD market is inefficient. For example, the results in Table 6 show that the average premium of the futures market is almost one euro, and the result is robust to controlling for the effects on supply and demand conditions in the spot market. Electricity markets are typically characterized by strong price variation caused by extreme changes in demand and supply conditions. In our data the single extreme demand occasion was the cold winter of 2009 - 2010. The spot market seems to have been affected by the cold winter conditions, whereas the futures market has not reacted. This implies that extreme market conditions offer opportunities for arbitrage trading in the futures market.

Future research could focus on several different areas. Probably the most promising direction would be to model the impact of the cold winter 2009 - 2010 and the structural change starting from the year 2012 more accurately. In our analysis this has been done by using dummy variables, but it may actually be an indication of nonlinear behavior of the EPAD futures premium caused by extreme temperature variations. From an economic point of view this raises the question whether there is enough predictability in the time series data for profitable trading. The second topic is how the electricity market price risk should be measured. It looks like the previous period's spot price variance and skewness may be poor predictors of future risks, especially under extreme conditions, as in the winter $2009-2010$. The third interesting topic is to test how the futures premium changes during the trading period of the contract, and how is it affected by the arrival of new market information.

\section{ACKNOWLEDGEMENTS}

The authors are grateful for the comments received on an earlier version of this paper in the 'Seminar on the Economic Analysis of Electricity Markets and Energy Literacy' organized by the University of Vaasa in February 2018, and to the anonymous referee for the comments on the manuscript of this paper. 
Appendix. Additional Tables

Table A1.

Descriptive statistics of Monthly EPAD, FIN-SYS spot price difference and futures premiums within different seasons. . *** and $*$ denote statistically different from zero at $1 \%$ and $10 \%$ risk levels for futures premiums.

\begin{tabular}{|c|c|c|c|c|c|c|c|}
\hline & $\mathrm{N}$ & Mean & Median & Variance & St. dev & Min & Max \\
\hline \multicolumn{8}{|l|}{ Spring } \\
\hline Monthly EPAD (€/MWh) & 30 & 2.59 & 1.31 & 8.73 & 2.95 & -2.60 & 8.37 \\
\hline FIN-SYS spot diff. (€/MWh) & 30 & 1.78 & 0.47 & 16.25 & 4.03 & -3.51 & 12.57 \\
\hline Futures premium $(€ / \mathrm{MWh})$ & & 0.81 & 0.60 & 7.00 & 2.65 & -5.89 & 10.19 \\
\hline \multicolumn{8}{|l|}{ Summer } \\
\hline Monthly EPAD (€/MWh) & & 5.00 & 3.01 & 26.47 & 5.14 & -2.76 & 16.30 \\
\hline FIN-SYS spot diff. (€/MWh) & 30 & 6.10 & 4.79 & 35.12 & 5.93 & -2.80 & 18.07 \\
\hline Futures premium $(€ / \mathrm{M}$ & 30 & $-1.09 *$ & -0.92 & 9.48 & 3.08 & -7.06 & 5.03 \\
\hline \multicolumn{8}{|l|}{ Autumn } \\
\hline Monthly EPAD (€/MWh) & 30 & 6.12 & 6.22 & 17.70 & 4.21 & -0.45 & 16.13 \\
\hline FIN-SYS spot diff. (€/MWh) & 30 & 4.57 & 3.62 & 20.59 & 4.54 & -2.90 & 15.65 \\
\hline Futures premium $(€ / \mathrm{MWh})$ & 30 & $1.55^{* * *}$ & 1.06 & 5.44 & 2.33 & -2.14 & 7.68 \\
\hline \multicolumn{8}{|l|}{ Winter } \\
\hline Monthly EPAD (€/MWh) & 31 & 4.41 & 3.82 & 9.75 & 3.12 & 0.36 & 12.46 \\
\hline FIN-SYS spot diff. (€/MWh) & 31 & 3.60 & 2.77 & 28.39 & 5.33 & -2.34 & 24.78 \\
\hline Futures premium $(€ / \mathrm{MWh})$ & 31 & 0.81 & 1.76 & 26.90 & 5.19 & -18.03 & 11.79 \\
\hline Winter excl. 12/2009-3/2010 & 28 & 4.41 & 3.76 & 10.23 & 3.20 & 0.36 & 12.46 \\
\hline
\end{tabular}


Monthly EPAD price (€/MWh)

FIN-SYS spot diff. (€/MWh)

1.45

9.62

3.10

$-2.34$

9.69

Futures premium $(€ / \mathrm{MWh})$

$282.05 * * * \quad 1.82$

10.51

3.24

$-7.04$

11.79

Table A2. Descriptive statistics of realized monthly water reservoir levels and deviation variables (realized historical average) in Finland, Sweden and Norway January 2006 - January 2016.

\begin{tabular}{l|ccccccc} 
& $\mathrm{N}$ & Mean & Median & Variance & St. dev & Min & Max \\
\hline Water reservoir level FIN (\%) & 121 & 60.15 & 62.25 & 195.92 & 14.00 & 18.80 & 81.67 \\
Water reservoir level SWE (\%) & 121 & 57.69 & 63.47 & 445.13 & 21.10 & 11.86 & 90.28 \\
Water reservoir level NOR (\%) & 121 & 61.84 & 64.46 & 375.29 & 19.37 & 17.87 & 92.68 \\
Water reservoir level diff. FIN (\%) & 121 & 0.89 & 2.20 & 73.47 & 8.57 & -18.23 & 17.67 \\
Water reservoir level diff. SWE (\%) & 121 & -0.61 & 0.07 & 60.20 & 7.76 & -17.29 & 15.71 \\
Water reservoir level diff. NOR (\%) & 121 & -1.82 & -0.72 & 64.43 & 8.03 & -21.60 & 12.24
\end{tabular}




\section{References}

Anderson, R., Danthine, J., 1983. Hedger diversity in futures markets. The Economic Journal 93, 370-389.

Bessembinder, H., Lemmon, M., 2002. Equilibrium pricing and optimal hedging in electricity forward markets. Journal of Finance 37, 1337-1382.

Entso-E., 2015. Maximum NTC. https://www.nordpoolspot.com/globalassets/downloadcenter/tso/max-ntc.pdf Accessed 21.12.2015.

Fama, E., French. K., 1987. Commodity futures prices: some evidence on forecast power, premiums, and the theory of storage. Journal of Business 60 (1), 55-73.

Finnish Energy Industries, 2015. Electricity net production, imports and exports (GWh) in Finland. http://energia.fi/en/node/1151. Accessed 30.1.2016.

Finnish Energy Industries, 2015. Temperature corrected electricity consumption. http://energia.fi/en/node/1151. Accessed 30.1.2016

Fleten, S., Hagen, L., 2015. The overnight risk premium in electricity forwards contracts. Energy Economics 39, 293-300.

Gjolberg, O., Brattested, T., 2011. The biased short-term futures price at Nord Pool: can it really be a risk premium? The Journal of Energy Markets 4, 3-18.

Granger, C., 1969. Investigating Causal relations by econometric models and cross-spectral methods. Econometrica 37, 424-438.

Hull, J., 2009. Options, futures, and other derivatives. 7th Edition. Pearson, Prentice Hall.

Kristiansen, T., 2004a. Pricing of contracts for difference in the Nordic market. Energy Policy, vol. 32. p. $1075-1085$.

Kristiansen, T., 2004b. Congestion management, transmission pricing and area price hedging in the Nordic region. Electrical Power and Energy Systems 26, 685-695.

Lucia, J., Torro, H., 2011. On the risk premium in Nordic electricity futures prices. International Review of Economics and Finance 20, 750-763. 
Marckhoff, J., Wimschulte J., 2009. Locational price spreads and the pricing of contracts for difference: Evidence from the Nordic market. Energy Economics 31, 257-268.

Nasdaq Omx, 2015. Our history.

http://www.nasdaqomx.com/transactions/markets/commodities/whoweare/ourhistory.

Accessed 20.12.2015

NordPool, 2015a. History. http://www.nordpoolspot.com/About-us/History/. Accessed 21.12.2015

NordPool, 2015b. Price calculation. http://www.nordpoolspot.com/TAS/Day-ahead-marketElspot/Price-calculation/. Accessed 21.12.2015

NordPool, 2015. Annual Report. http://nordpoolspot.com/globalassets/download-center/rulesand-regulations/. Accessed 2.6.2016

NordReg (Nordic Energy Regulators), 2011. NordREG report on the price peaks in the Nordic wholesale market during winter 2009-2010. Report 1/2011.

NordReg (Nordic Energy Regulators), 2014. Nordic Market Report 2014 - Development in the Nordic Electricity Market. Report 4/2014.

Redl, C., Haas, R., Huber, C. Böhm, B., 2009. Price formation in electricity forward markets and the relevance of systematic forecast errors. Energy Economics, 31, 356-364.

Spodniak, P. 2015. Informational Efficiency on the Nordic Electricity Market - the Case of European Price Area Differentials (EPAD). International Conference on the European Energy Markets - EEM15. Lisbon.

Spodniak, P., Chernenko, N., Nilsson, M., 2014. Efficiency of Contracts for Differences (CfDs) in the Nordic Electricity Market. TIGER Forum: Ninth Confer-ence of Energy Industry at a Crossroads: Preparing the Low Carbon Future. Toulouse. 5.-6.6.2014. Carbon Future

Spodiak, P., Collan, M., Makkonen, M., 2017. On long-term transmission rights in the Nordic electricity markets. Energies 10, 1-19. http://dx.doi.org/10.3390/en10030295.

Spodniak, P, Collan, M., 2018. Forward risk premia in long-term transmission rights: The case of electricity price area differentials (EPAD) in the Nordic electricity market. Utilities Policy 50, 194-206.

Vehviläinen, I., 2002. Basics of electricity derivative pricing in competitive markets. Applied Mathematical Finance 9, 45-60.

Weron, R., Zator, M., 2014. Revisiting the relationship between spot and futures prices in the Nord Pool electricity market. Energy Economics 44, 178-190.

Viljainen, S., Makkonen, M., Gore, O., Spodniak, P., 2012. Risk in small electricity markets: The experience of Finland in winter 2012. The Electricity Journal 25 71-80. 
HIGHLIGHTS of the article:

Pricing of Electricity Futures Based on Locational Price Differences: The Case of Finland

- The market for Finnish electricity futures has been inefficient based on the most recent data

- Demand and supply side fundamentals have a role to play in the pricing

- Russian exports restrictions have had a strong effect on the Finnish electricity market pricing

- There has been a significant positive excess futures premium in the Finnish market

- Financial market participants should have been able to utilize this also in economic terms 